Journal of Educational

and Psychological Sciences

Volume (5), Issue (32) : 30 Aug 2021

P: $43-59$

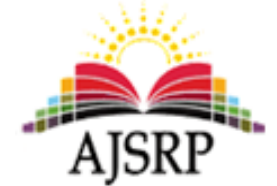

ISSN: 2522-3399

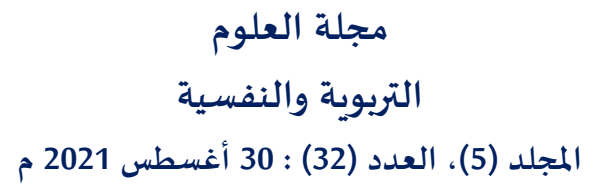

ص: 43 - 59

\title{
Effectiveness of Using Micro Learning Through Web 2.0 Tools in Developing Skills of Multimedia Designing and Production Among 12th Grade Students in Palestine
}

\author{
Abdelrahman Mohammad Sadeq Abu Sarah \\ Faculty of Educational Sciences || Al-Quds Open University || Palestine
}

\begin{abstract}
This research aimed to investigate effectiveness of using micro learning through Web 2.0 tools in developing skills of multimedia designing and production among 12th grade students in Palestine. The study used a one-group pretestposttest experimental design, while the research sample consisted of (11) second secondary grade students / technology stream in one of Qabatia Directorate of Education schools, in the academic year 2020/2021. A practical performance measurement and a note card were also prepared. After Applying procedures and tools of the research, the results showed a statistically significant difference between the two average degrees of the pretest and the posttest, in favor of the posttest with great influence. In addition, using micro learning through Web 2.0 tools achieved effectiveness (according to Black equation) in developing students' skills of multimedia designing and production. In light of these results, the researcher suggested a number of recommendations, including: Employing micro learning through Web 2.0 tools in information technology and applied sciences in general, and programming and automation in particular; training teachers and educational supervisors on micro learning content design through digital applications in order to develop different skills among students.
\end{abstract}

Keywords: Micro learning, Web 2.0 tools, Multimedia.

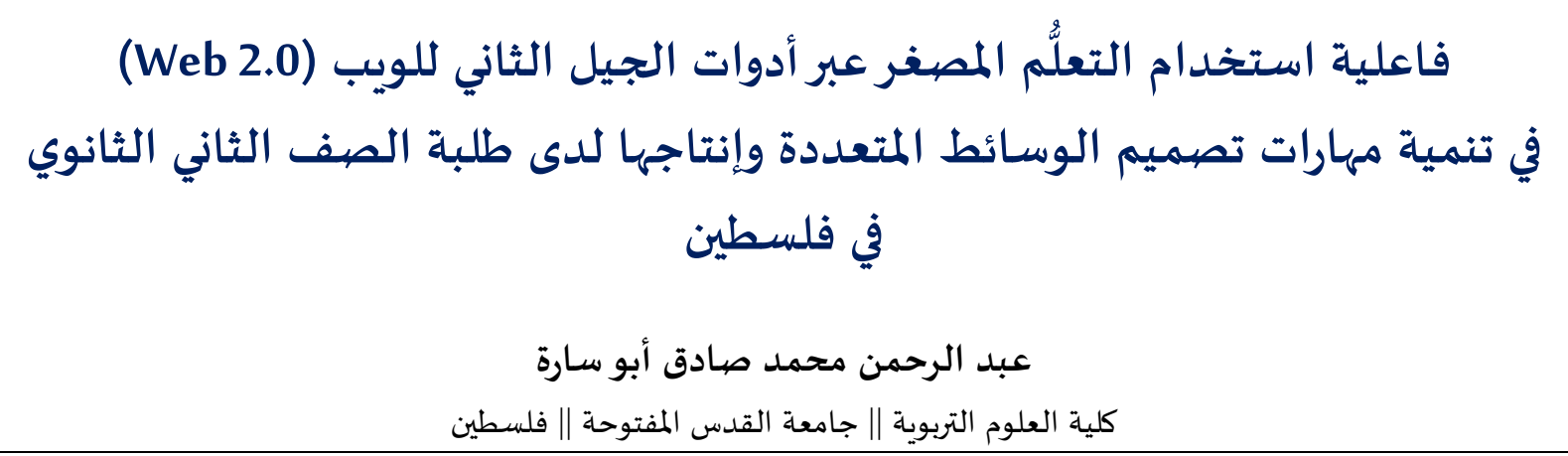

المستخلص: هدف هذا البحث إلى تقصي فاعلية استخدام التعلُّم المصغر عبر أدوات الجيل الثاني للويب (Web, 2.0) في تنمية مهارات

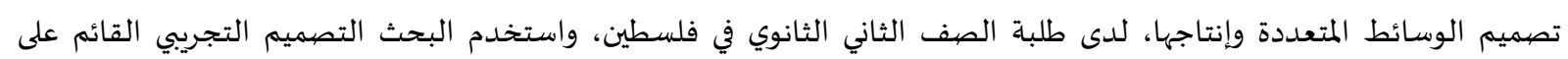

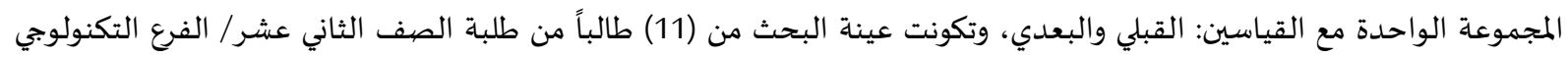

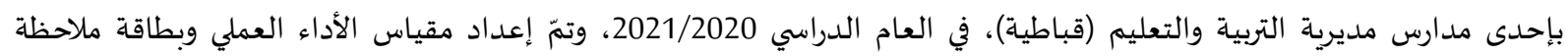
خاصية باه، وبعد تطبيق إجراءات البحث وأدواته، أشارت النتائج إلى وجود فرق دال إحصائياً، بين متوسطي درجات الطلبة في في القياسين:

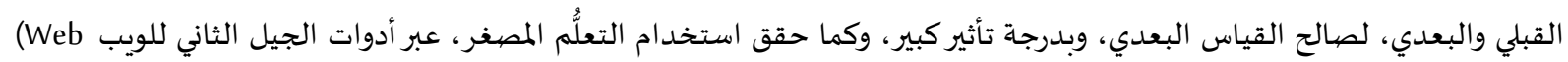

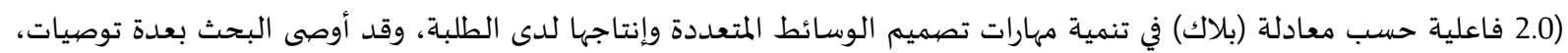

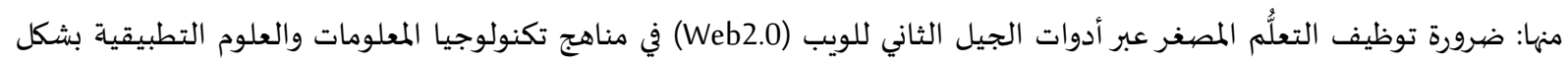


عام، وفي تدرس مادة البرمجة والأتمتة بشكل خاص، وبضرورة تدريب المعلمين والمشرفين، على تصميم المحتوى التعليمي المصغر، عبر

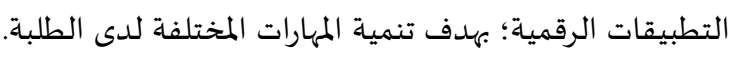

يزخر عالمنا المعاصر بالكثير من المستحدثات الرقمية، التي تؤثر على مجتمعاتنا العربية تارة بطريقة إيجابية

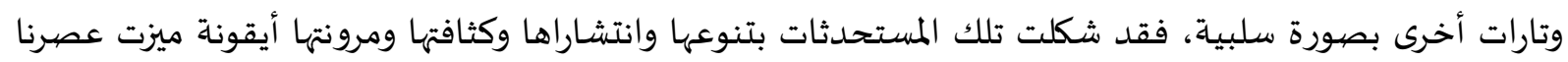

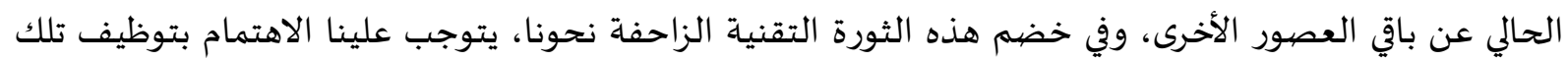

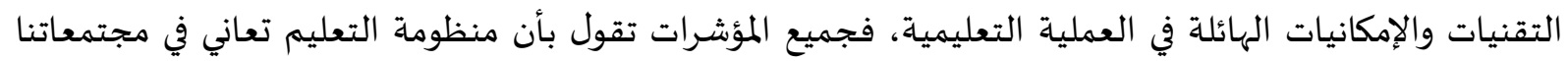

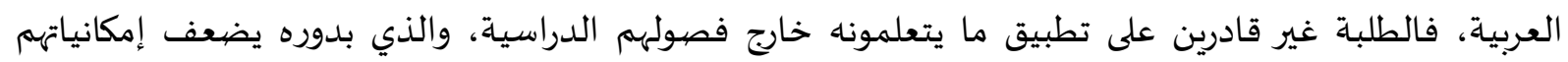
ومهاراتهم العملية في سوق العمل، مما يسهم بالتالي في خسارة مجتمعاتنا العربية الكثير من الثروات المتاحة، وفئي مقدمتها ثروة العلم والمعرفة. يُعد التعلم المصغر (Micro learning) أسلوباً حديثاً في مجال التعليم والتعلم في عصر التقنية، حيث يستند

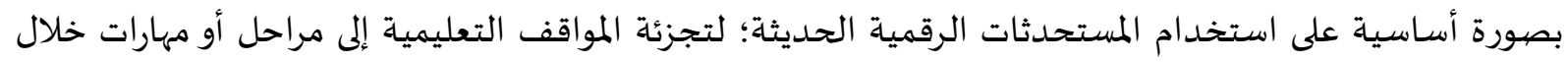

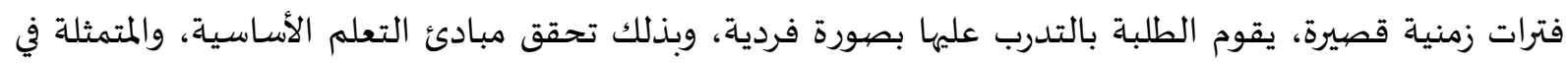
تحليل المهارات إلى السلوك المرغوب، وتبسيط مواقف التعلم واستخدام التغذية الراجعة لتطوير المهارات المكتسبة لدى الطلبة (بشارة، 2005).

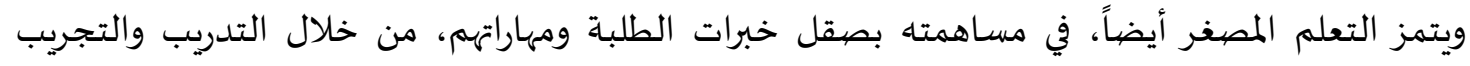

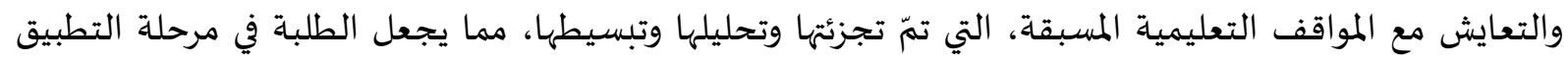

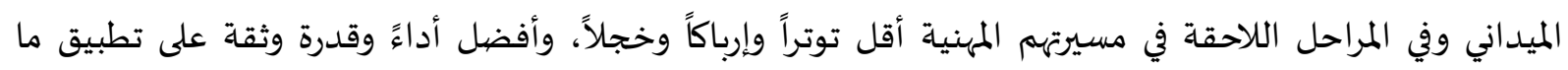
يتعلمونه بصورة ملموسة، تحقق المخرجات التعليمية المأمولة منهم (العتوم، 2018).

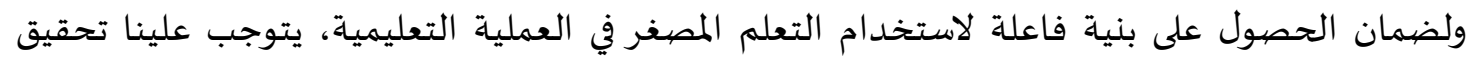

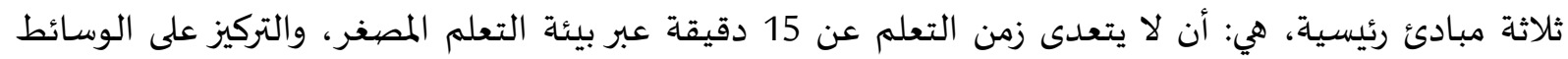

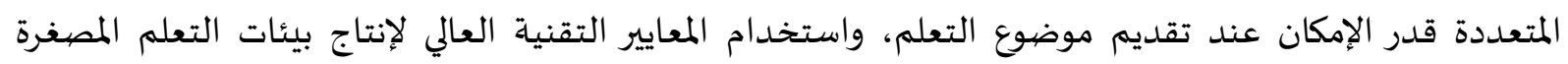

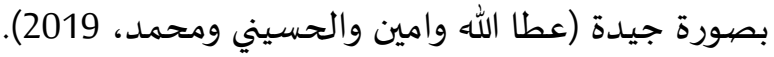
ولكي يستطيع التعلم المصغر تحقيق أهدافه، والمتمثلة في تنمية قدرة الطلبة على تطبيق ما يتعلمونها

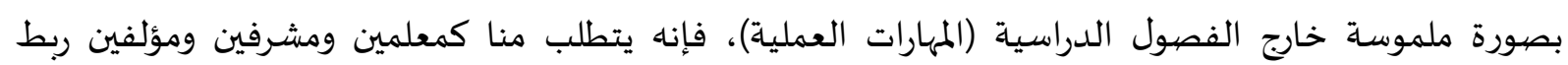
استراتيجيات التعلم المصغر مع أدوات التكنولوجيا الرقمية الحديثة، التي توفر لنا الكثير من الإمكانيات والمزايا لدعم

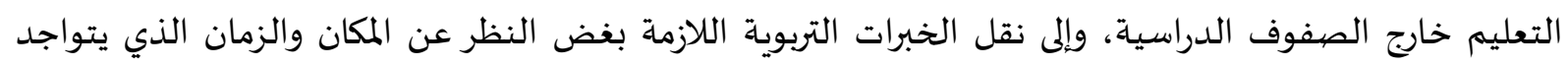

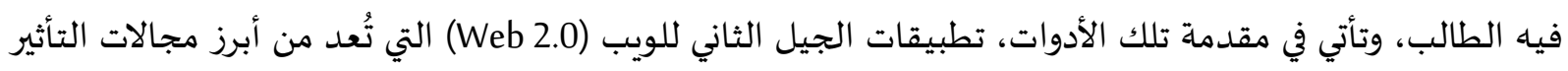
في عالمنا المعاصر.

إن أهمية استخدام تطبيقات الجيل الثاني للويب (WEB. 2.0) في التعليم، تكمن في تسهيلها لعملية

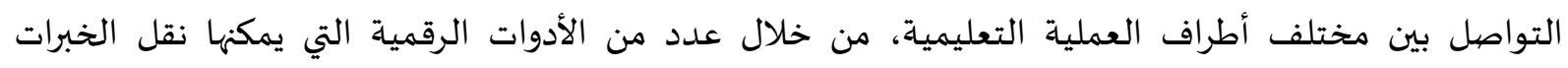

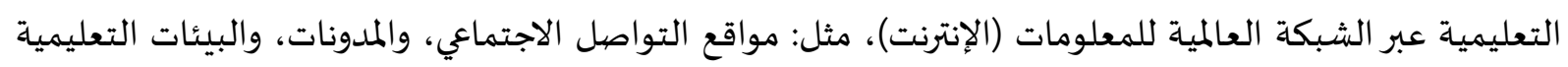

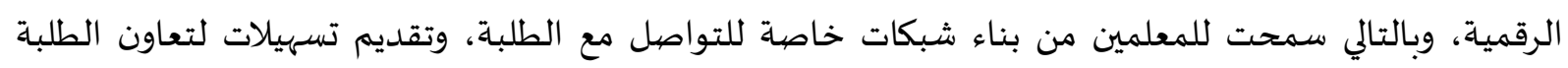


داخل الفصول الدراسية وخارجها، وإلى تقديم الفرص الحقيقية للمتعلمين للإبداع والتميز في المجالات التعليمية المختلفة (دوفي وماكدونالد، 2018).

وتتميز أدوات الجيل الثاني للويب (WEB. 2.0) بتوفيرها العديد من الأدوات الرقمية التي تعزز التفاعل بين

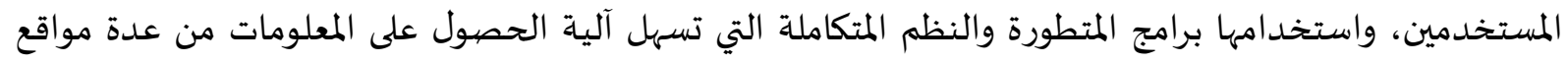

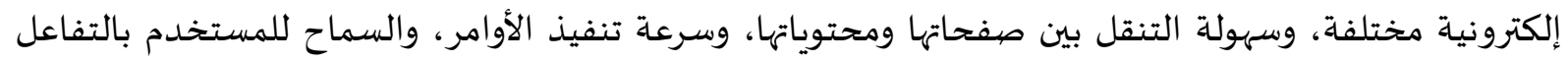

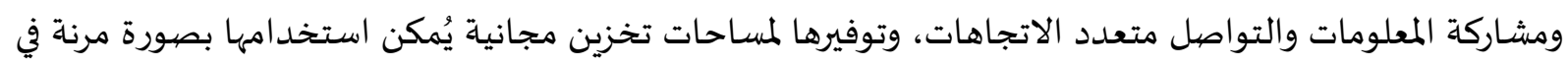

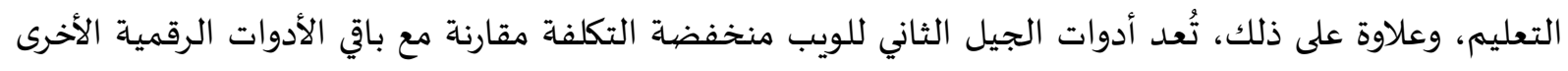
مما يجعلها في متناول من يمتلك جهاز الحاسوب (الجمل، 2015).

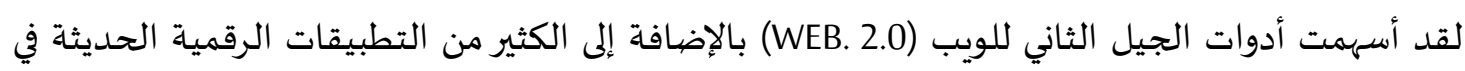

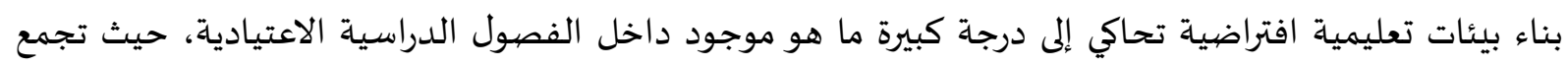

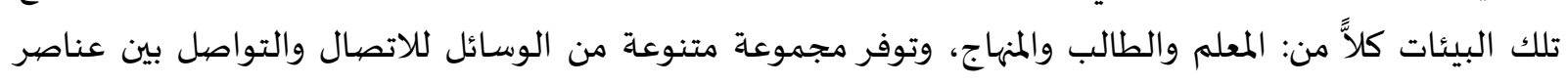

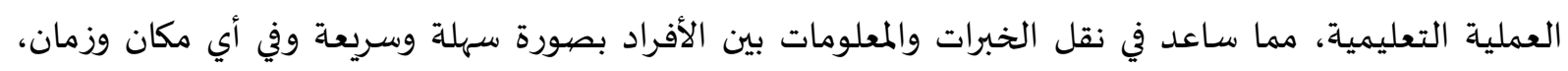

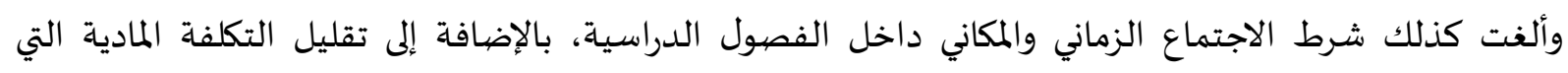

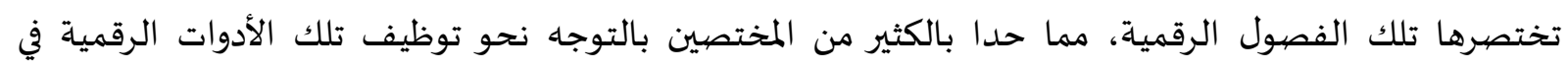
التعليم (أبو سارة، 2020 أ ؛ أبو سارة وياسين، 2018 ؛ صالحة ألفة وأبو سارة، 2019).

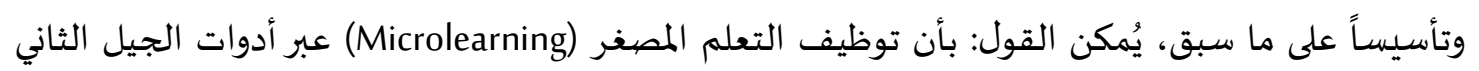
للويب (WEB 2.0) تحقق العديد من المزايا والتي توضحها النقاط النقاط الآتية:

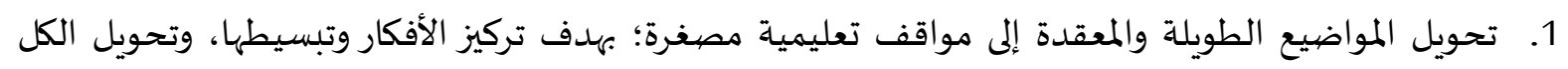
المعقد إلى أجزاء مبسطة ليستطيع الطالب فهمها وإدراكها عن بُعدة.

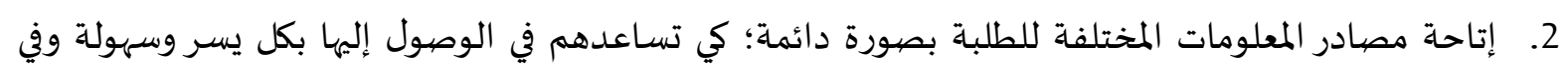
أي وقت ومكان يرغبون. 3. زيادة الزمن الفعلي للتعلم، وذلك بعدم حصرئ عملية التعلم بالفصول الدراسية المدرسية، بل جعلها عملية مستمرة وواسعة تشمل البيئة الصفية والمنزل. 4. مساعدة الطلبة على اكتساب مهارات (تعلم كيف تتعلم) وذلك من خلال تزويدهم بأدوات ومصهادر معلوماتية مختلفة، تمكنهم من التعلم بشكل مستقل وفعال. 5. الحصول على المصادر التعليمية بشكل مباشر، دون الحاجة إلى تخزينها وتثبيتها على أجهزة الحاسوب الشخصية.

ونظراً لأهمية التكنولوجيا والتطبيقات الرقمية في واقع حياتنا المعاصرة، حرصت وزارة التربية والتعليم

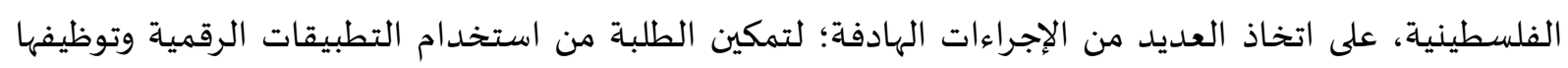

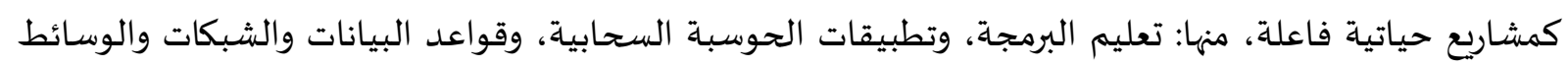

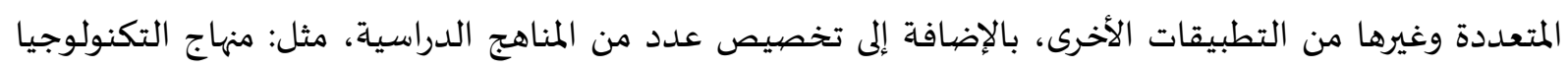

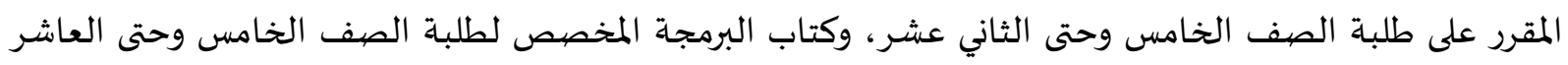

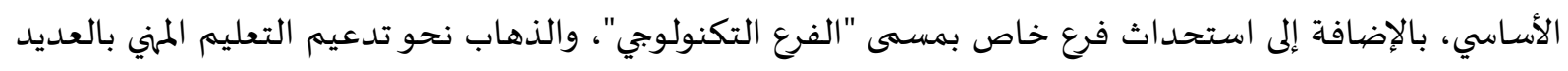

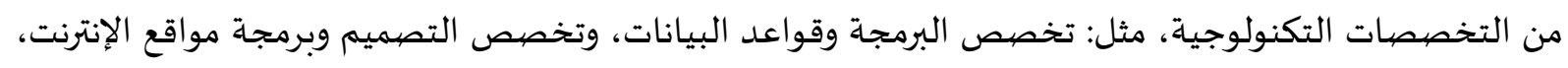
وتخصص تطبيقات الوسائط المتعددة (أبو سارة، 2020 أ). 
تسهم الوسائط المتعددة في إعطاء الفرصة أمام الطلبة؛ ليكونوا باحثين عن المعلومات الحديثة من خلال

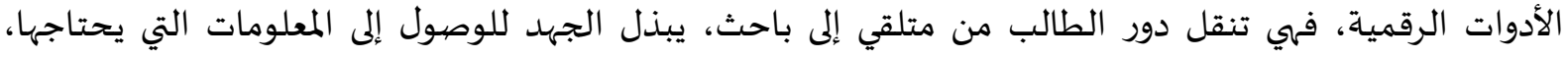

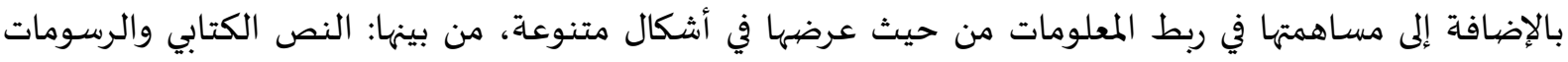

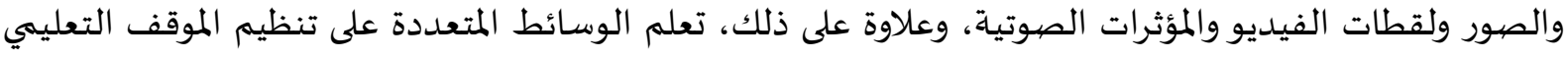
المصغر، وتنمية عنصري: المثابرة والمشاركة لدى الطلبة (المشهراوي، 2017).

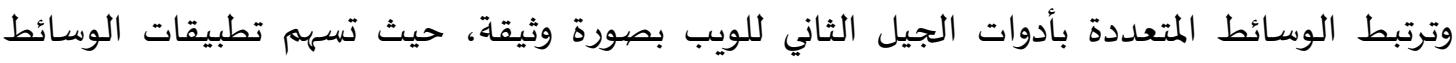

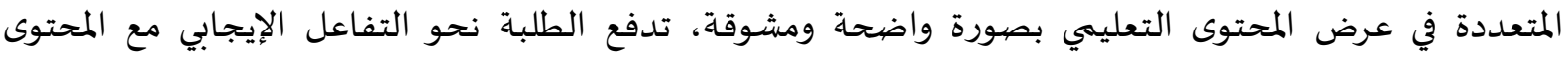

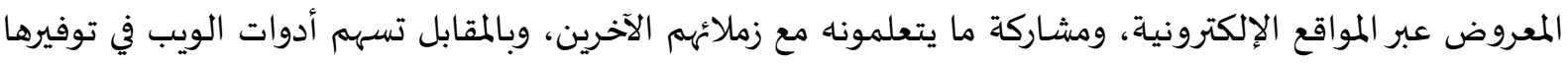
مساحات رقمية يُمكن من خلال تخزين المحتوى التعليمي الخاص بالوسائط المتعددة، بالإضافة إلى تخصيصهيا العديد من الأدوات التي يُمكنها تشغيل محتوى الوسائط المتعددة وتعديله تخديله (فارس وإسماعيل، 2017).

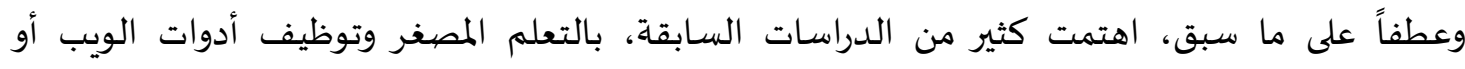
تطبيقات الوسائط المتعددة في التعليم، نذكر منها: دراسة القرني (2020) التي أشارت إلى فاعلية توظيف الماتفئ التعلم

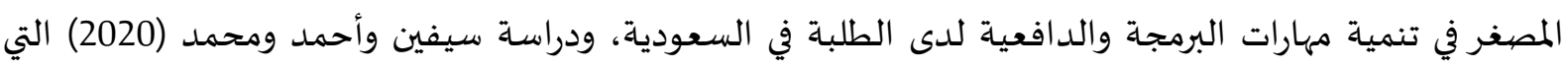
أشارت إلى فاعلية استخدام أدوات الويب في تنمية مهارات استخدام تطبيقات الحوسبة السحابية، لدئ لدى معلمي

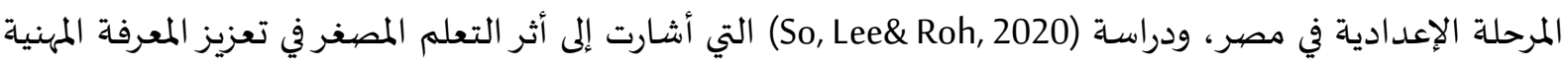

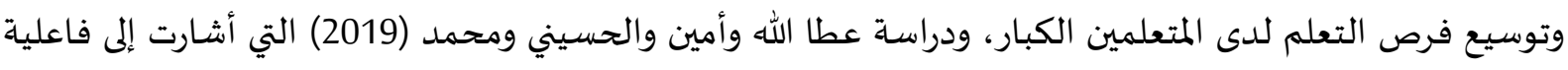

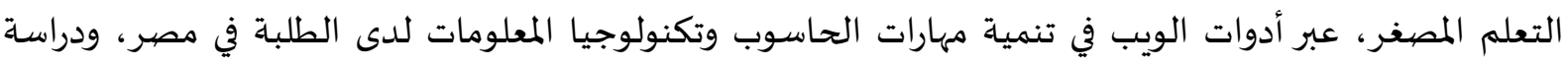

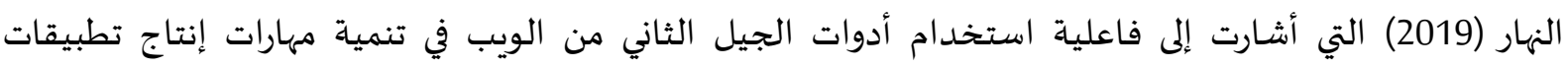

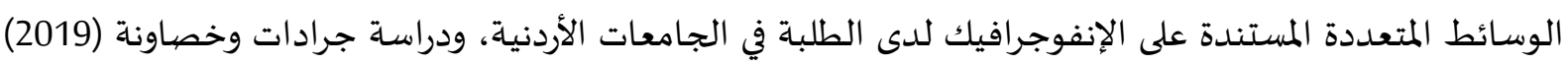

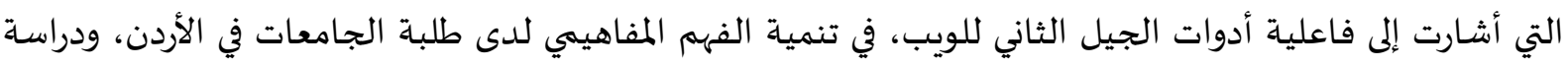
(Skalka \& Drlik, 2018)

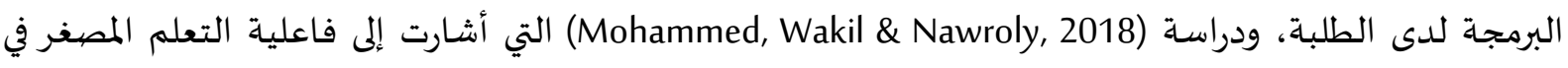

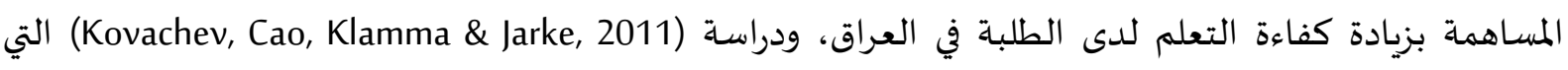
أشارت إلى دور التعلم المصغر، عبر بيئات الجوال في دعم عمليات التعلم وطرق تقديم المحتوى التعليمي داخل

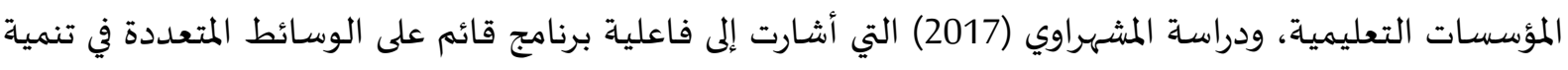
مهارات الاستماع لدى الطلبة في فلسطين، ودراسة عودة (2016) التي أشارت إلى فاعلية التدريس باستخدات

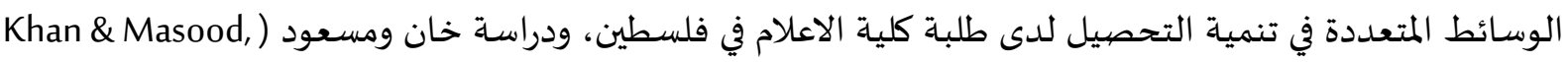

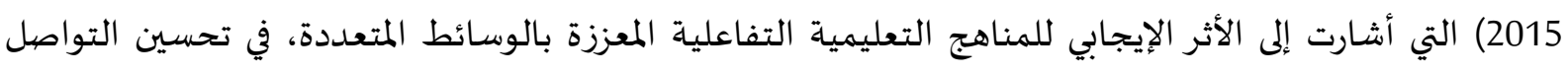

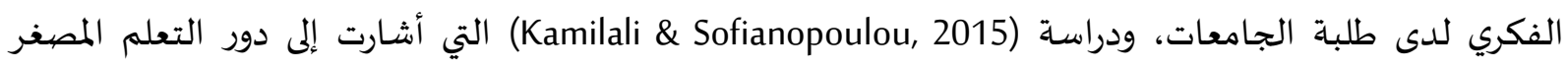
والتعلم المتنقل في تطوير أنشطة التعلم المبكر لدى الطلبة، وإلى قدرتها على إتاحة المصادر التعليمية بصهورة مستمرة،

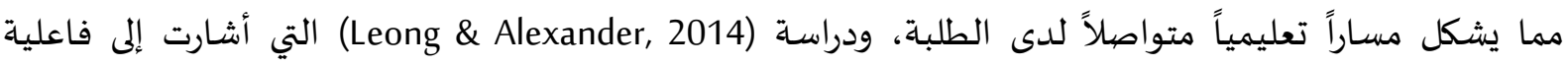

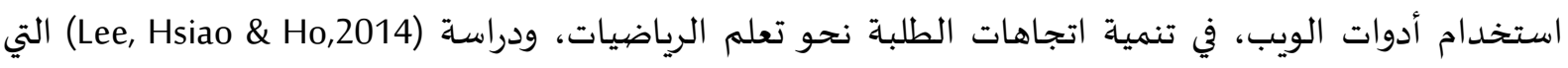

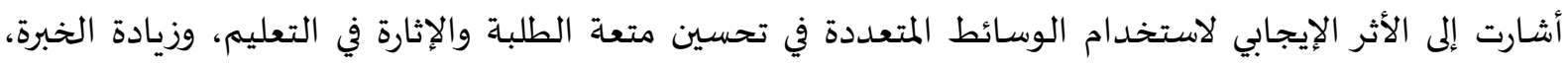

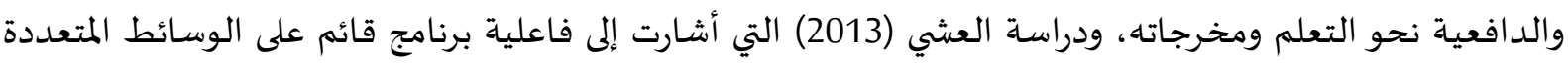
في تنمية المبادئ العلمية ومهارات التفكير البصري في فلسطين. 
وتأسيساً على ما سبق، تأتي هذه الدراسة لتقصي فاعلية التعلم المصغر (Microlearning) عبر أدوات الجيل الثاني للويب، في تنمية مهارات تصميم الوسائط المتعددة وإنتاجها لدى طلبة الصف الثانياني الثانوي في فلسطين.

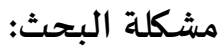

تنبع مشكلة الدراسة من واقع الإجراءات التي اتخذتها وزارة التربية والتعليم الفلسطينية، سعياً لتطوير

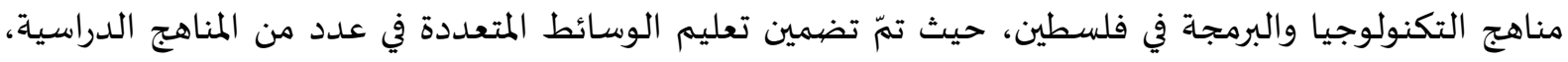

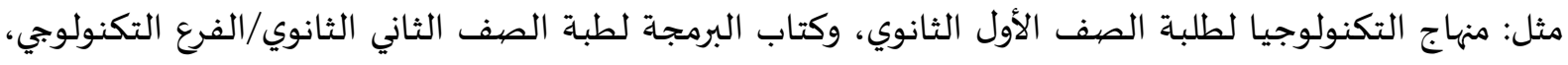
بالإضافة إلى استحداث العديد من التخصصيات المهنية المرتبطة بالوسائط المتعددة، مثل: تخصص التصائ التصهيم

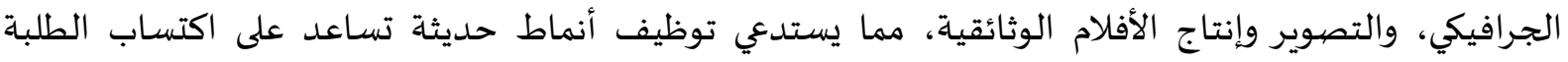

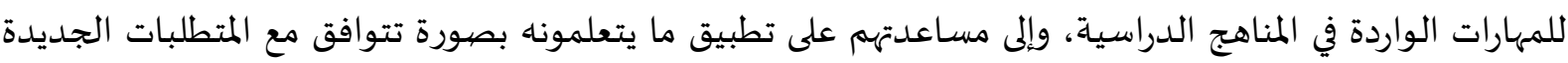
والمستحدثة لسوق العمل. وأمام ذلك الجهد فقد لاحظ الباحث، من خلال عمله معلماً للمرحلة الثانوية (الفرع التكنولوجي)، ضعفاً

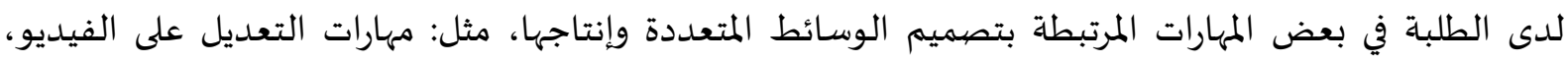

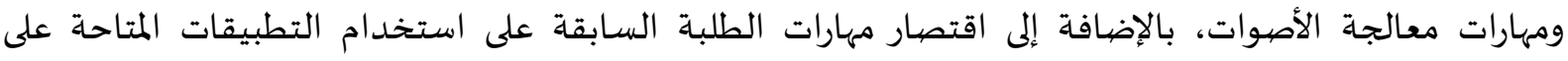

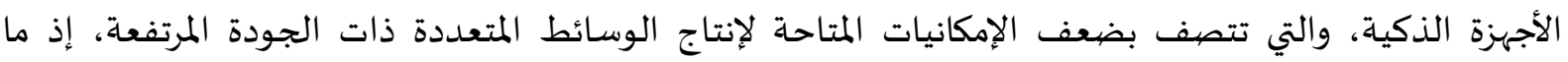

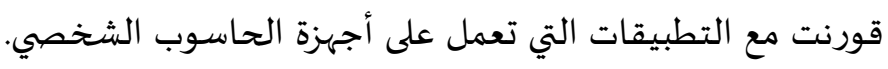
وعطفاً على ما سبق، أشارت العديد من الدراسات السابقة إلى مشكلة ضعف التهف مهارات تصميم الوسائط

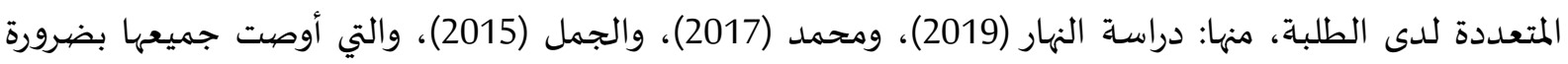

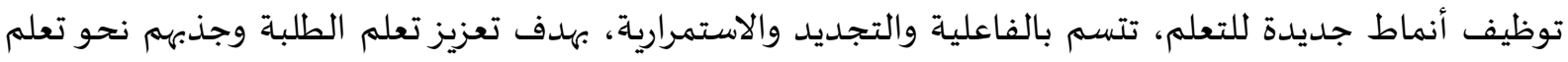

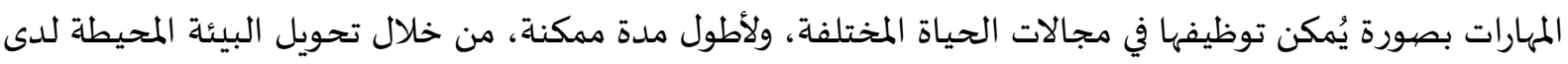

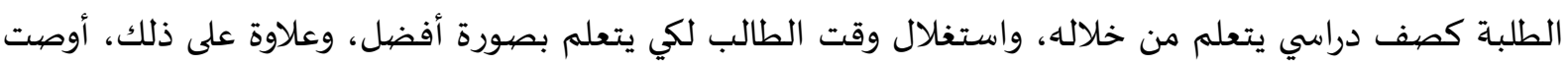

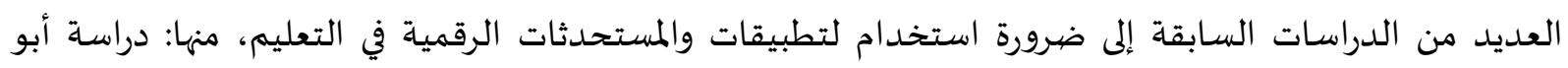

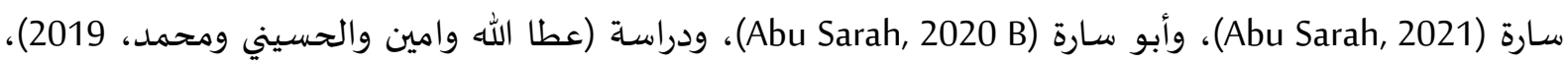

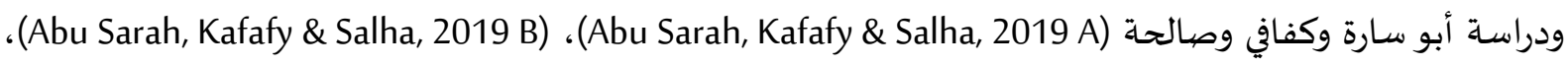

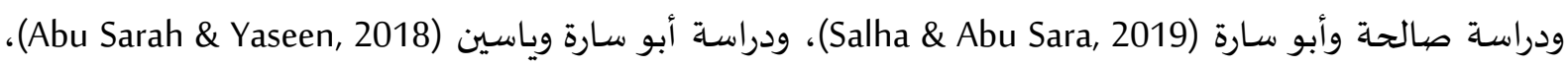
ودراسة القاضي (2016)، ودراسة العشي (2013) وغيرها من الدراسات الأخرى.

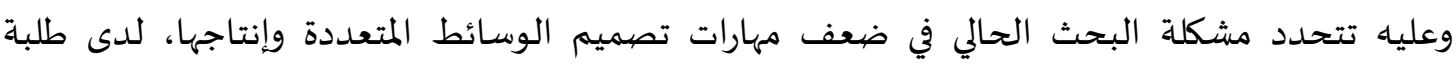

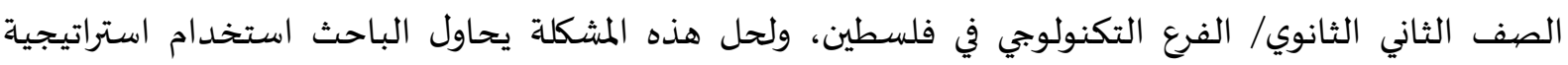

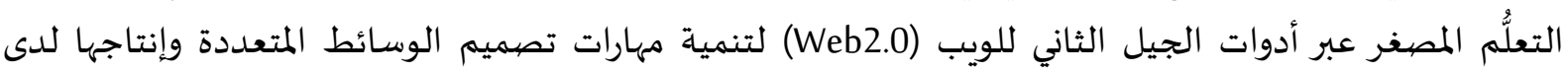

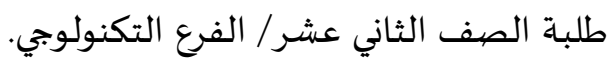

أسئلة البحث:

تتحدد مشكلة البحث في الأسئلة الآتية:

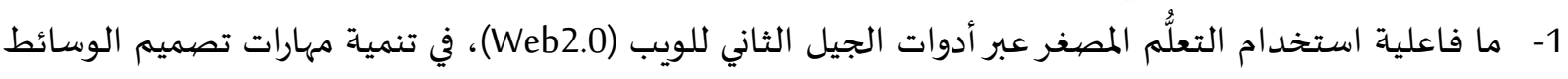

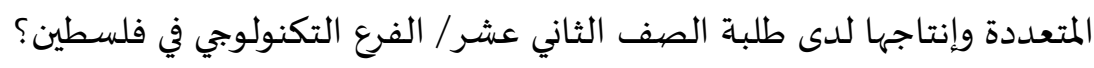


2- هل يحقق استخدام التعلُّم المصغر، عبر أدوات الجيل الثاني للويب (Web2.0)، فاعلية في تنمية مهارات تصميم

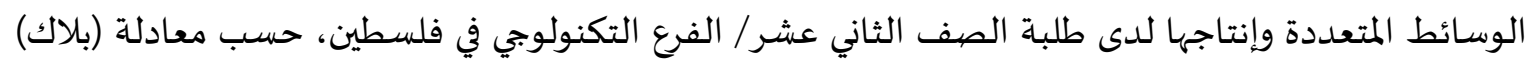

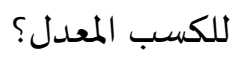

$$
\text { فرضيات البحث: }
$$

تتمثل فروض البحث في الآتي:

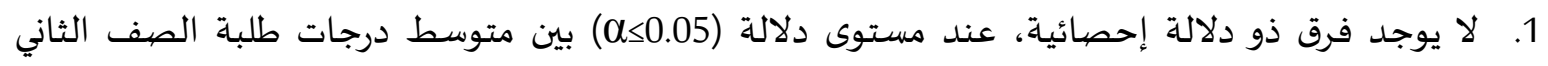

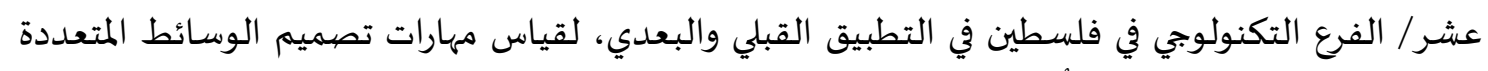

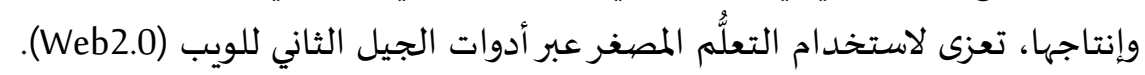

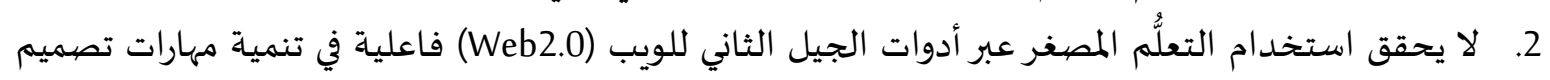

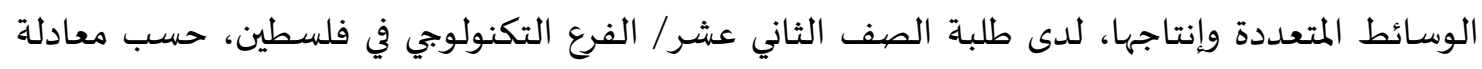

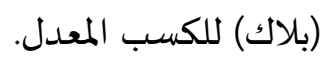

أهداف البحث:

يهدف البحث إلى تحقيق ما يأتي:

1. تنمية مهارات تصميم الوسائط المتعددة وإنتاجها، لدى طلبة الصفئ الثفائ الثاني عشر/ الفرع التكنولوجي في

2. قياس فاعلية استخدام استراتيجية التعلُّم المصغر عبر أدوات الجيل الثاني للويب (Web2.0)، في تنمية مهارات تصميم الوسائط المتعددة وإنتاجها، لدى طلبة الصف الثيانية التعب عشر / الفرع التكنولوجي في فلسطين.

أهمية البحث:

تأتي أهمية هذه الدراسة باستنادها على نمط تدريسي حديث قائم على التعلُم المصغر عبر أدوات الجيل

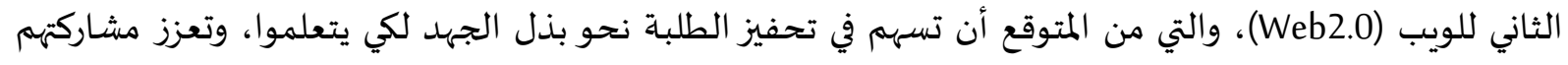

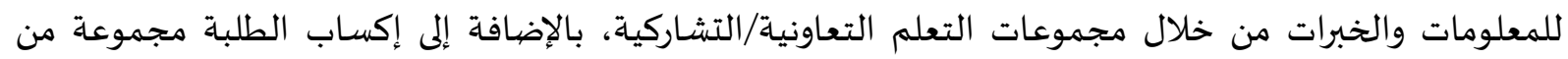

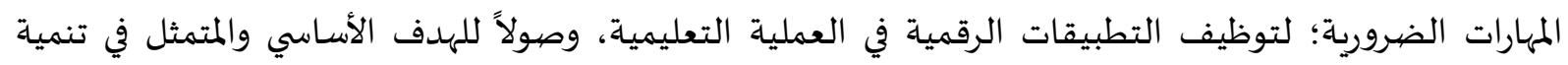

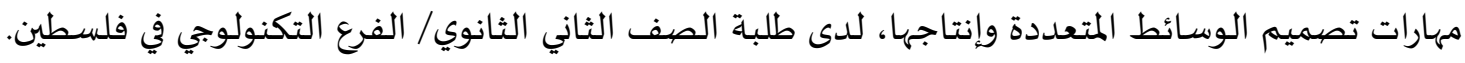
وعلاوة على ذلك، قد تساعد هذه الدراسة المعلمين والطلبة على توظيف كثير من المفاهيم والمهارات

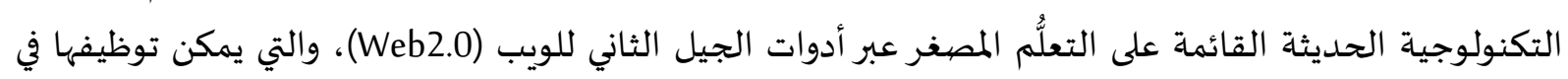

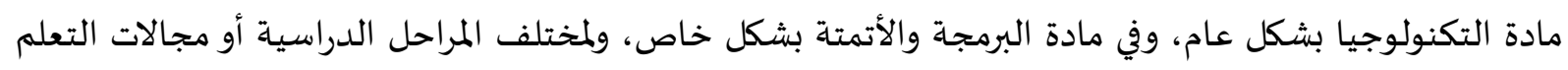

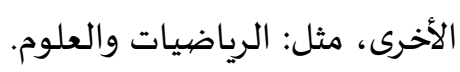

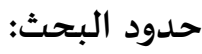
تقتصر حدود البحث على الآتي:

الحدود الموضوعية: فاعلية استخدام التعلُّم المصغر عبر أدوات الجيل الثاني للويب (Web 2.0) في تنمية مهارات تصيميم الوسائط المتعددة وإنتاجها. 
الحدود البشرية: عينة من طلبة الصف الثاني عشر/ الفرع التكنولوجي بمدرسة (عزت أبو الرب الثانوية)، وهي

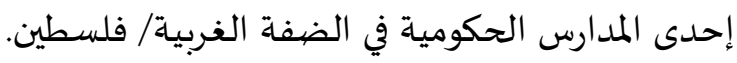
الحدود الزمنية: هذا البحث في تعميم نتائجهاه على تطبيقه خلال الفصليه الفيل الدراسي الثاني من العام الدراسي .2021/2020

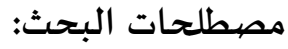

- أولاً: التعلم المصفر (Microlearning): يعرف على أنه أنها طريقة لتقديم المحتوى التعليمي بصورة رقمية من

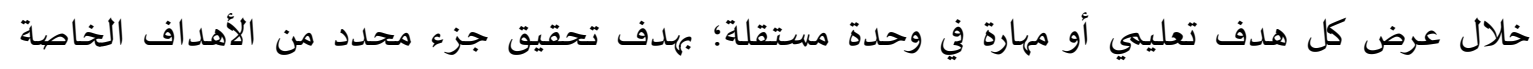

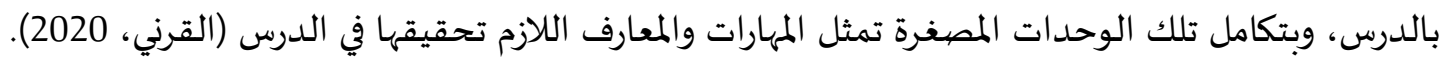

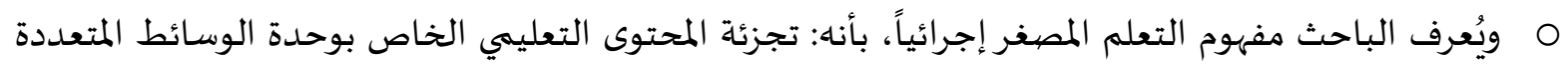

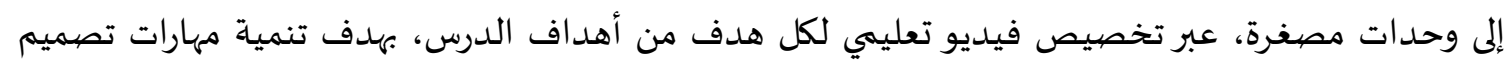

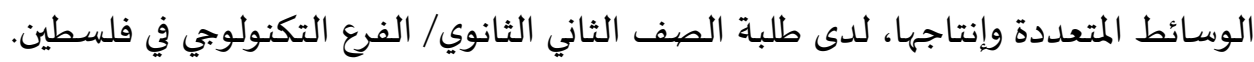

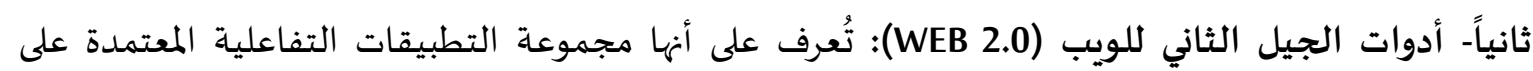

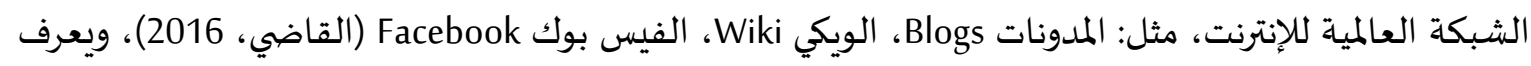

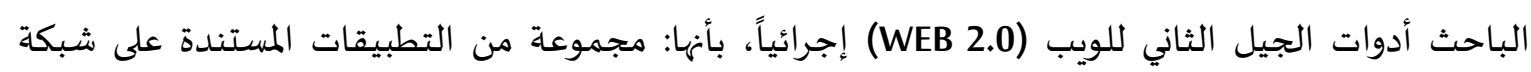

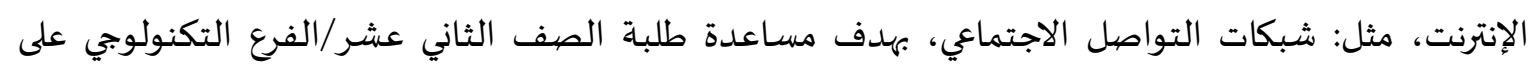
تعلم مهارات تصميم الوسائط المتعددة وإنتاجها.

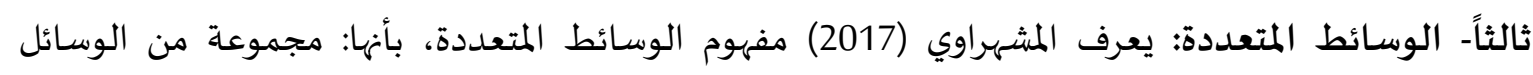

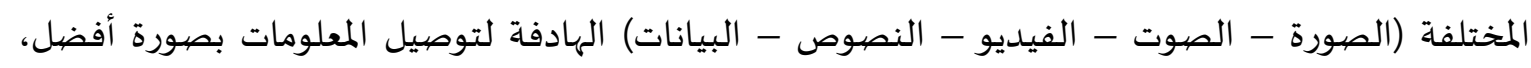
ولتحفيز الطلبة على التفاعل بغية تحقيق الأهداف التعليمية.

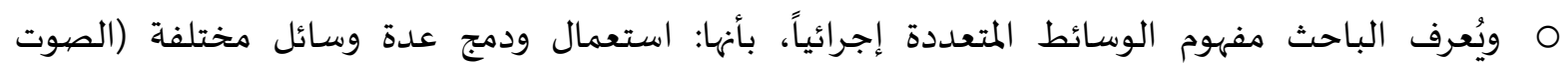
والصورة والفيديو والرسومات والنصوص والبيانات والألوان) لتقديم محتوى تعليمي يؤثر على عدد من من إندان الحواس، لتحقيق أهداف تعليمية محددة مسبقاً.

استخدم الباحث المنهج التجريبي بتصميم المجموعة الواحدة اختبار (قبلي - بعدي)؛ لاستقصاء فاعلية

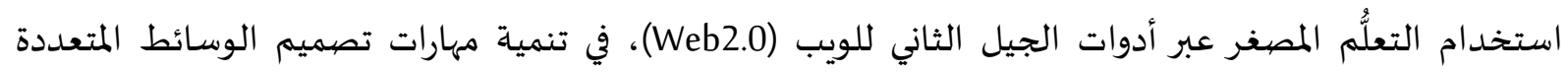

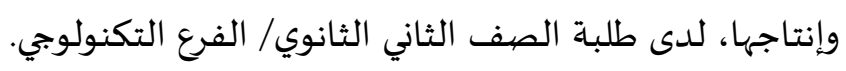
ثانياً: مجتمع البحث: تكوّن مجتمع الدراسة من جميع طلاب الصف الثاني عشر / الفرع التكنولوجي، المسجلين في وزارة التربية

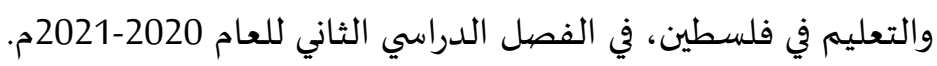


تكونت عينة البحث من (11) طالباً من طلاب الصف الثاني عشر/ الفرع التكنولوجي بمدرسة عزت أبو الرب الثانوية، التابعة لمديرية التربية والتعليم (قباطية) في الضفة الغربية في فلسطين.

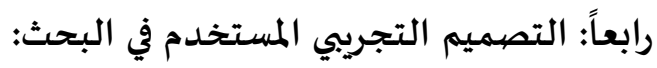
اعتمد البحث على التصميم القائم على المجموعاة الواحدة، مع استخدي المعام القياس القبلي/البعدي على عينة

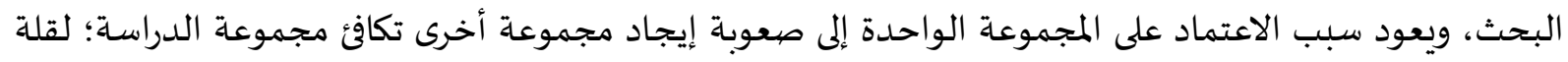

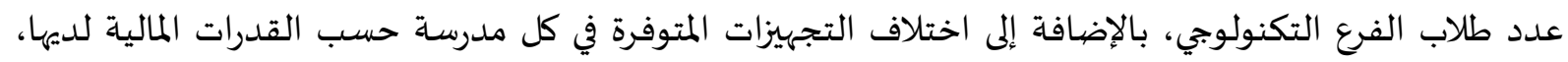

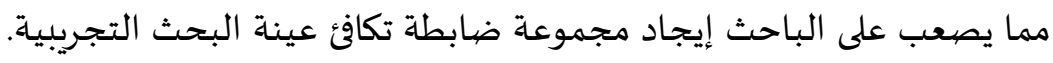

خامساً: مهارات تحليل الوسائط المتعددة وإنتاجها:

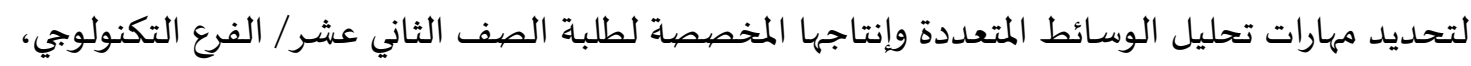

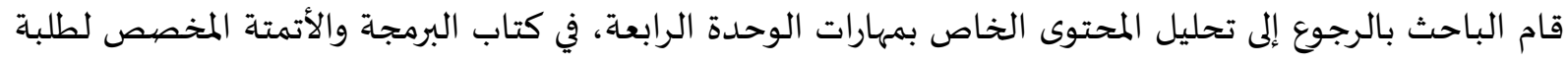

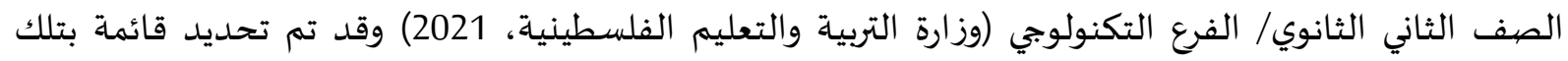

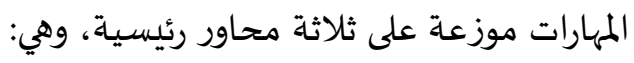

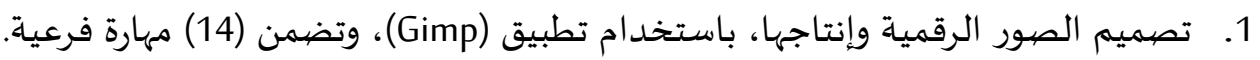

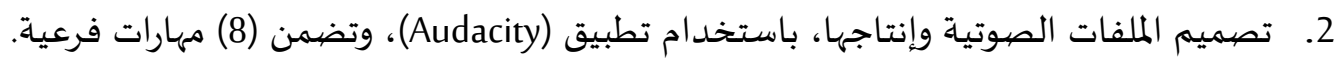

$$
\begin{aligned}
& \text { 3. تصميم الفيديو وإنتاجاه، باستخدام تطبيق (VSDC)، وتضمن (10) مهارات فرعية. }
\end{aligned}
$$

سادساً: أداتي البحث:

قام الباحث بإعداد مقياس الأداء العلمي وبطاقة ملاحظة خاصة به؛ لقياس مهارات تصميم الوسائط

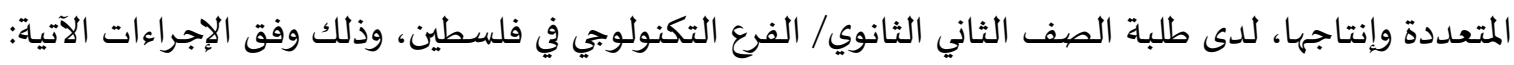

تصيميم مقياس الأداء العملي: قام الباحث بإعداد مقياس الأداء العملي الخاص بوحدة الوسائط المتعددة، وتكون المقياس بصورته

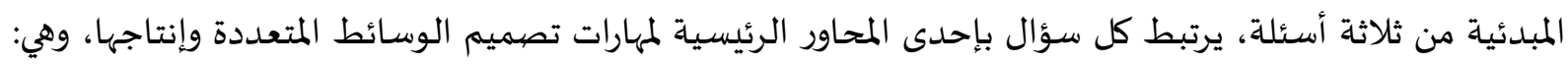

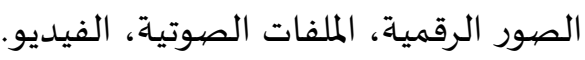

صددق مقياس الأداء العلمي: تمّ التحقق من صبدق مقياس الأداء العلمي، من خلال عرضيه على مجموعة من المحكمين، ضمت مجمت مجموعة

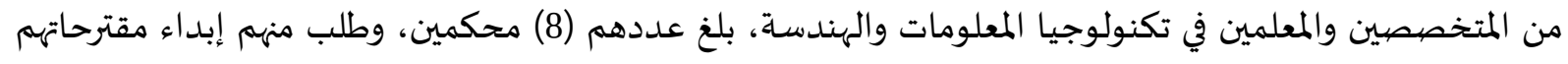

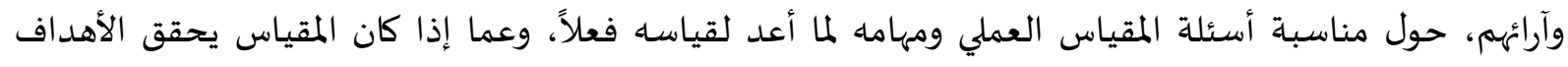

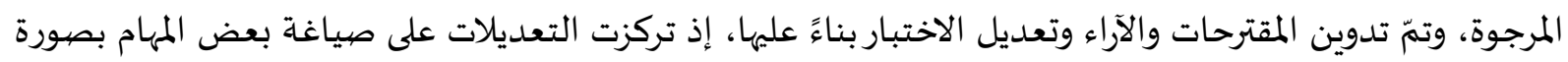

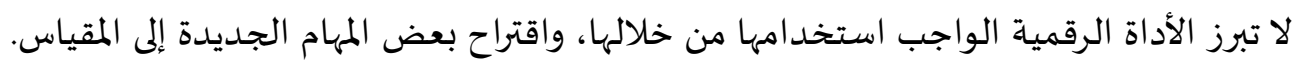


تصهيم بطاقة الملاحظة الخاصية بمقياس الأداء العلمي:

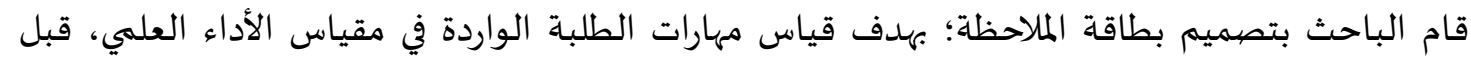

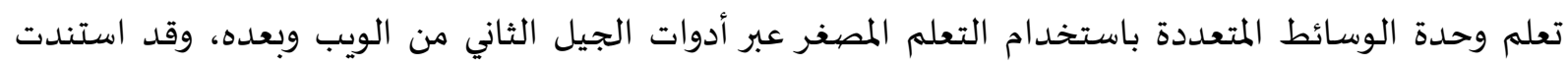

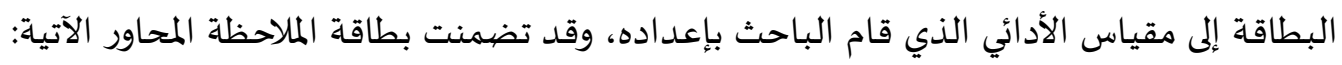

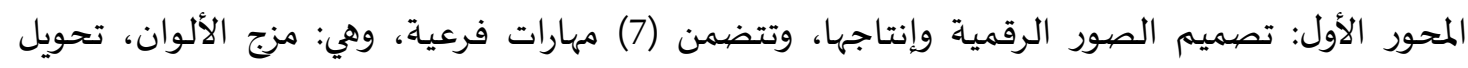

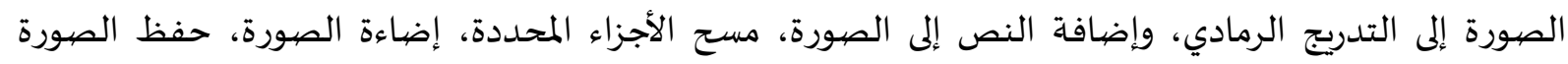
بصيغة مناسبة. المحور الثاني: تصميم الملفات الصهوتية وإنتاجها، وتتضمن (4) مهارات فرعية، وهي: تحديد المدة الزمنية للملف الصوتي، تنقية الملف الصوتي من الضوضاء، دمج الملفات الصوتية، حفظ الملفات الصوتية بصيغة مناسبة.

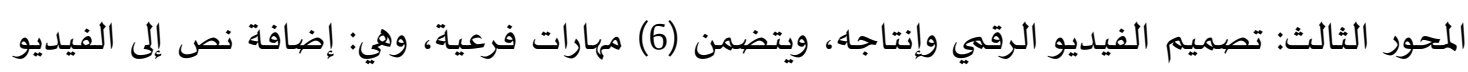

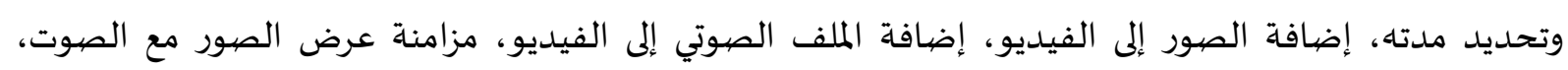
حفظ الفيديو بصيغة مناسبة.

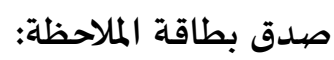
تمّ التحقق من صدق بطاقة الملاحظة، من خلال عرضها على مجموعة من المحكمين، ضمت مجمتهوعة من

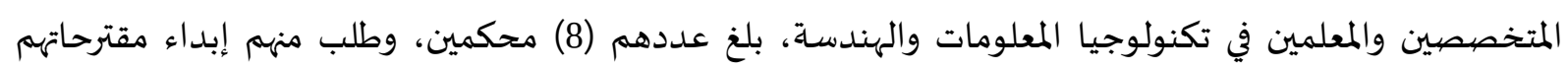

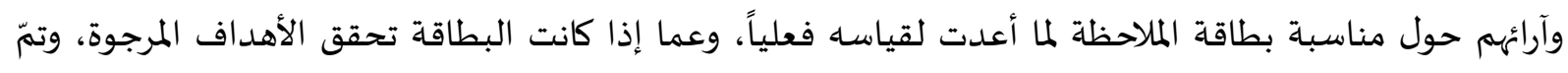

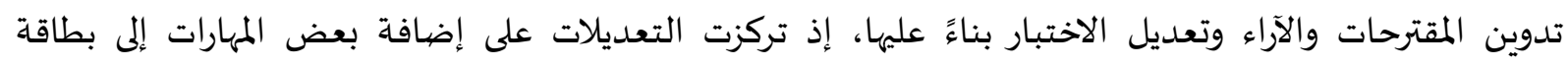

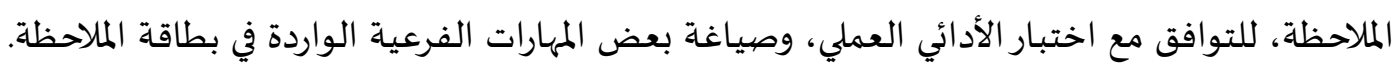

ثبات بطاقة الملاحظة: قام الباحث بالتحقق من ثبات بطاقة الملاحظة، من خلال حساب معادلة (ألفا كرونباخ) بواسطة برنامج الرزمة الإحصائية للعلوم الاجتماعية (SPSS) وبلغت قيمة معامل الثبات لفقرات الاختبار (0.946) وهي قيمة مقبولة تربوياً لأغراض البحث (شعيب وشعيب، 2016).

إجراءات تطبيق تجربة البحث الميدانية: أولاً: إعداد الدروس التعليمية المصغرة : قام البدى الباحث بتقسيم دروس وحدة الوسائط المتعددة، الواردة في

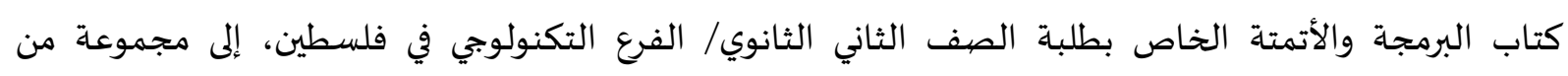

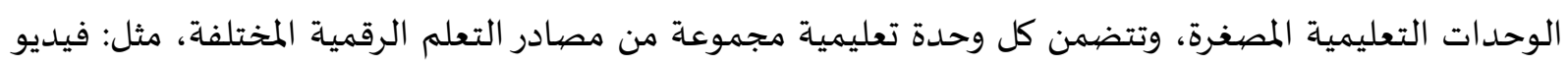

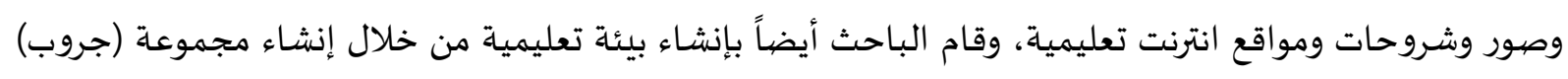

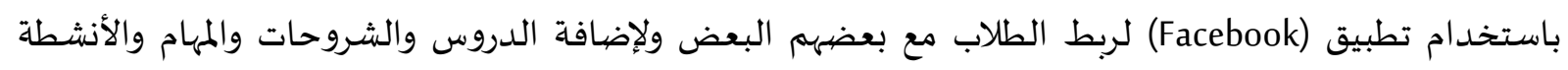

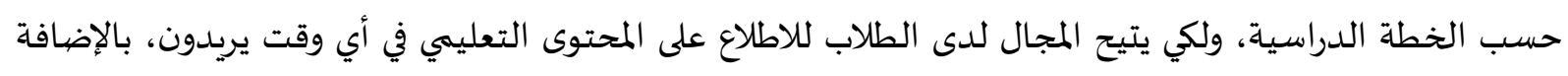
إلى تمكين الطالب من التواصل مع المعلم وزملائه الآخرين.

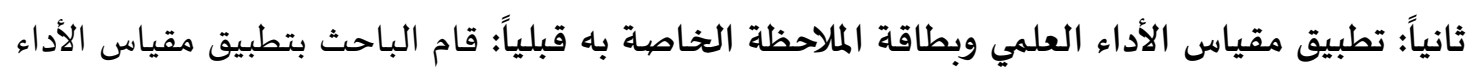

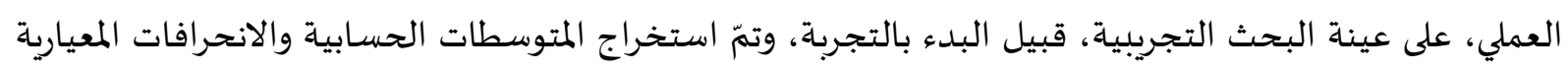

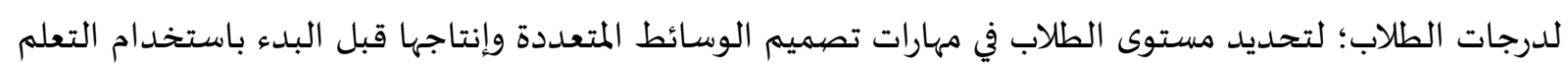


المصغر، عبر أدوات الجيل الثاني من الويب (WEB 2.0)، وقام الباحث بتصحيحه، وتسجيل الدرجات بواسطة بطاقة الملاحظة لطلبة المجموعة التجريبية.

ثالثاً: التدريس باستخدام التعلم المصغر، عبر أدوات الجيل الثاني للويب (التجربة العملية): بدأ الباحث

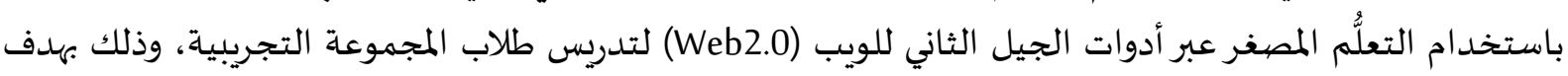

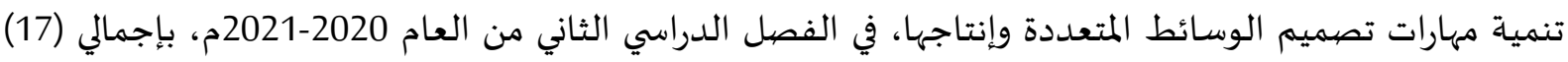

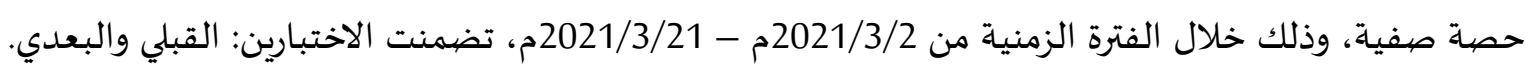
رابعاً: التطبيق البعدي لأدوات البحث: تمّ تطبيق مقياس الأداء العملي على طلبة المجمموعاة التجريبية، وتمّ منّم

رصد النتائج بواسطة بطاقة الملاحظة. خامساً: المعالجة الإحصائية: لتحليل نتائج البحث الحالي ؛ استخدم الماتئة الباحث الرزمة الإحصائية للعلوم

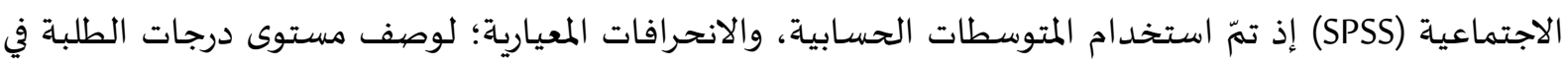

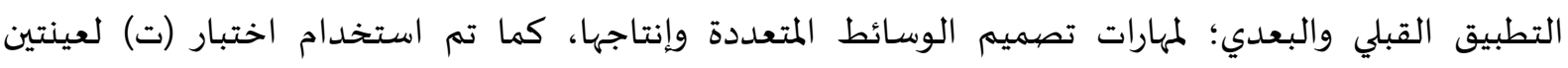
مرتبطتين (Dependent Sample T-test) لدلالة الفرق بين متوسطي درجات طلاب المجموعة التجريبية في التطبيق

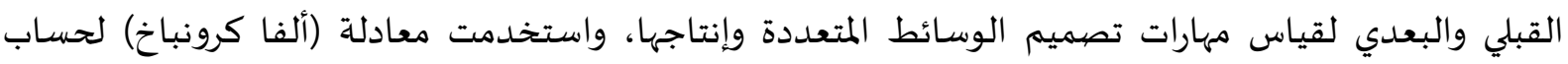

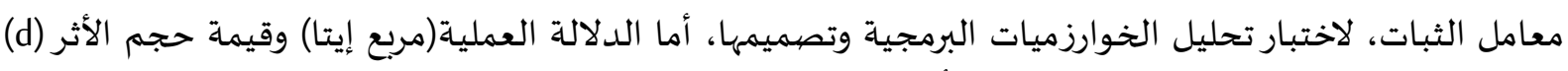

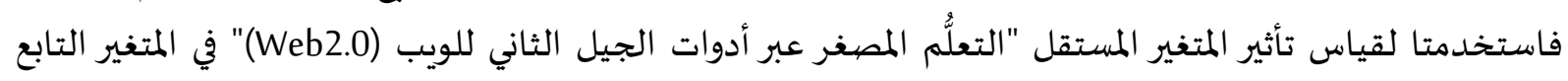

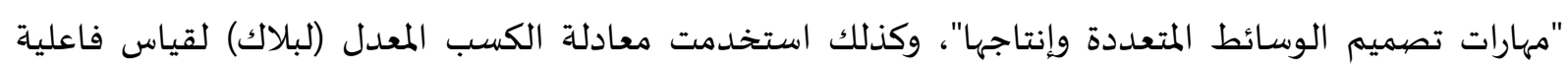

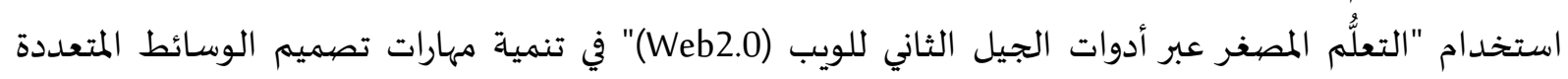
وإنتاجها.

\section{نتائج البحث وتفسيرها:}

أولاً- للإجابة عن السؤال الأول: "ما أثر استخدام التعلُم المصغر عبر أدوات الجيل الثاني للويب (Web2.0)

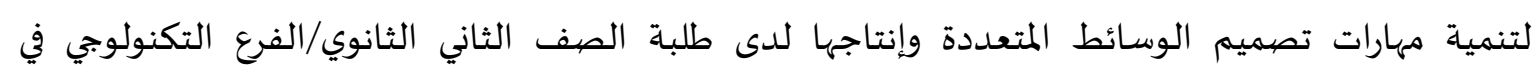
فلسطين؟"، تمّّ صياغة الفرض الصفئري الآتي:

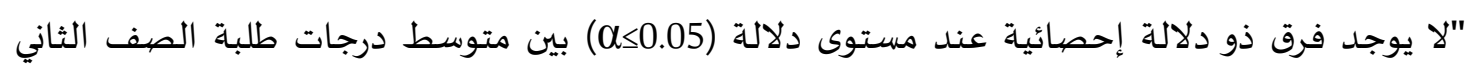

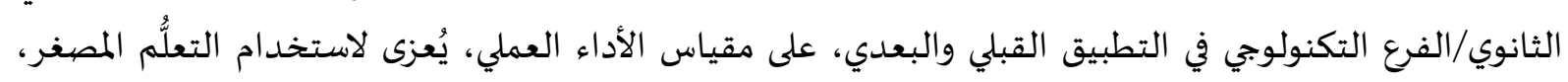

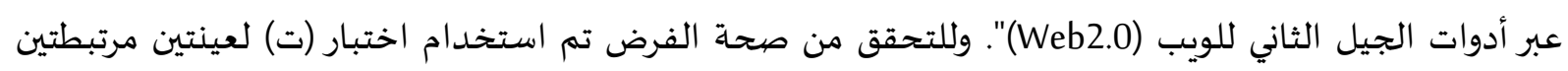
(Dependent Sample T-test) جدول (1): نتائج اختبار (ت) لعينتين مرتبطتين (Dependent Sample T-test) لاختبار دلالة الفروق في الاختبار

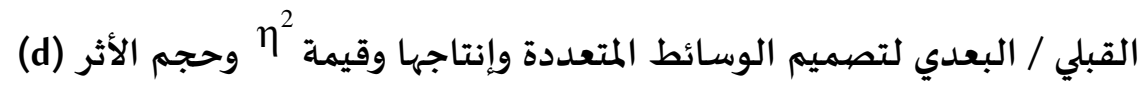

\begin{tabular}{|c|c|c|c|c|c|c|c|c|}
\hline $\begin{array}{c}\text { الأثر (d) } \\
\text { (d) }\end{array}$ & مربع إيتا & مستوى الدلالة & درجات & قيمة & الانحراف & المتوسط الحسابي & التطبيق & المجالات \\
\hline 8.82 & \multirow{2}{*}{0.91} & دالة عند & \multirow{2}{*}{10} & \multirow{2}{*}{10.68} & 1.80 & 1.45 & القبلي & \multirow{2}{*}{ الصور الرقمية } \\
\hline كبير & & $(0.01)$ & & & 2.29 & 10.45 & البعدي & \\
\hline 7.27 & 0.93 & دالة عند & 10 & 12.38 & 1.04 & 0.90 & القبلي & الملفات الصهوتية \\
\hline
\end{tabular}




\begin{tabular}{|c|c|c|c|c|c|c|c|c|}
\hline الأثر (d)م & مربح إيتا & مستوى الدلالة & درجات & قيمة & الانحراف & المتوسط الحسابي & التطبيق & المجالات \\
\hline كبير & & $(0.01)$ & & & 1.03 & 7.45 & البعدي & \\
\hline $\begin{array}{l}3.13 \\
\text { كبير }\end{array}$ & 0.71 & دالة عند & 10 & 5.00 & $\begin{array}{l}1.48 \\
4.68\end{array}$ & $\begin{array}{l}1.72 \\
9.18\end{array}$ & البعديلي & الفيديو \\
\hline كبير 16.19 & 0.98 & دالة عند & 10 & 8.67 & $\begin{array}{l}3.93 \\
7.59\end{array}$ & $\begin{array}{c}3.63 \\
27.09\end{array}$ & البعدبي & الدرجة الكلية \\
\hline
\end{tabular}

يتبين من الجدول (1) السابق وجود فرق ذي دلالة إحصائية عند المستوى (0.01 0 )، بين متوسط درجات

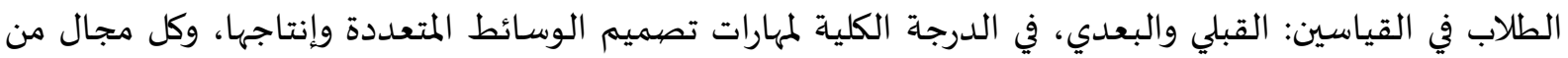

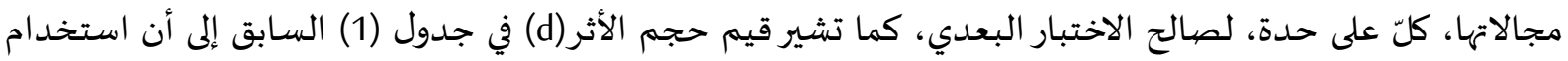

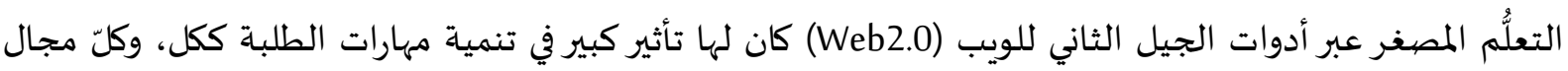

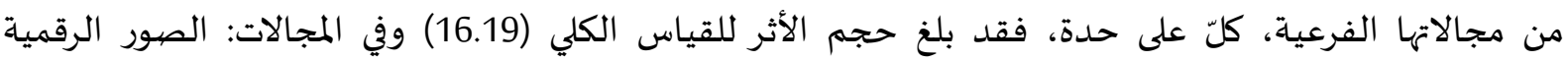

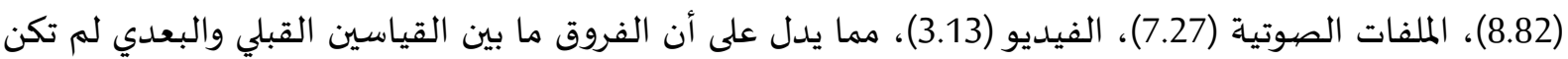

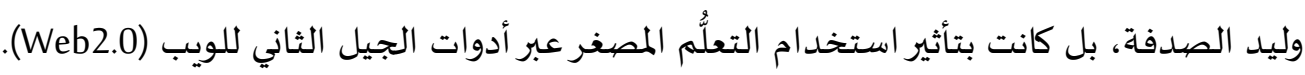

ثانياً: للإجابة عن السؤال الثاني: " هل يحقق استخدام التعلُم المصغر، عبر أدوات الجيل الثاني للويب

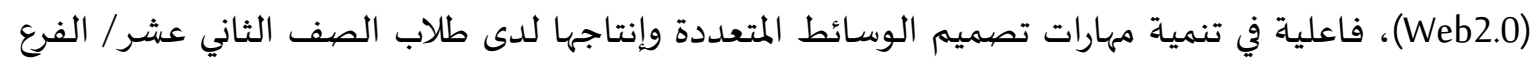

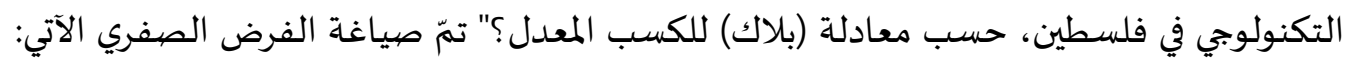

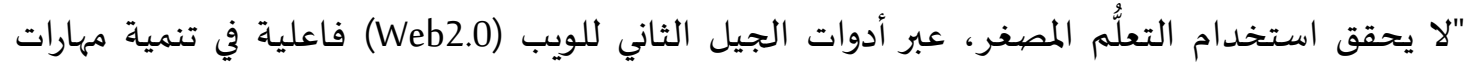

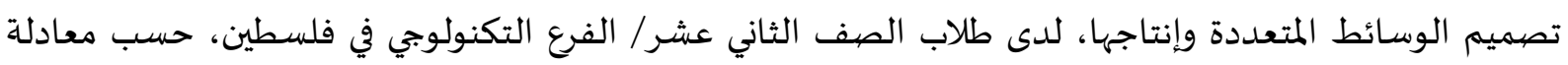
(بلاك) للكسب المعدل". وللتحقق من صحة الفرض تم استخدام معادلة بلاك (Black) لنسبة الكسب المعدل، وجدول (2) يبين ذلك.

جدول (2): نسبة الكسب المعدل (لبلاك) حول فاعلية التعلم المعكوس في تنمية مهارات تحليل الخوارزميات

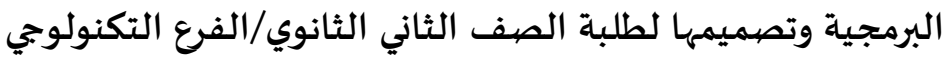

\begin{tabular}{|c|c|c|c|c|}
\hline نسبة الكسب & الدرجة العظمى للاختبار & المتوسط البعدي & المتوسط القبلي & المجالات \\
\hline 1.60 & 12 & 10.45 & 1.45 & الصور الرقمية \\
\hline 1.74 & 8 & 7.45 & 0.90 & الملفات الصيوتية \\
\hline 1.39 & 12 & 9.18 & 1.27 & الفيديو \\
\hline 1.556 & 32 & 27.09 & 3.63 & الدرجة الكلية \\
\hline
\end{tabular}

مدى بلاك المقترح للكسب المعدل يتراوح بين (1.0 إلى 2.0) يتبين من جدول (2) السابق، أن نسبة الكسب المعدل التي حققها استخدام التعلُّم المصغر، لمبر عبر أدوات

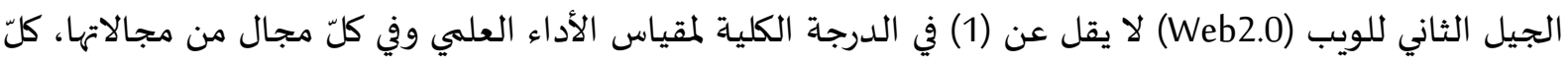

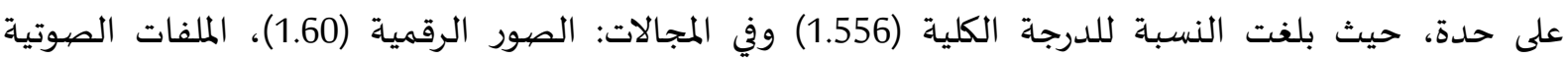

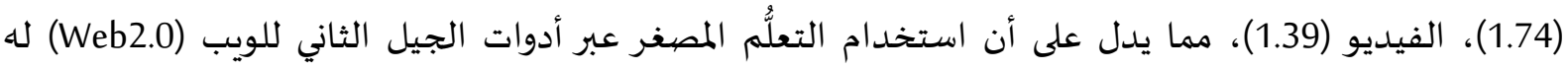

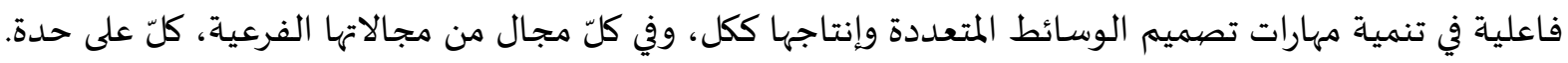




\section{مناقشـة النتائج وتفسيرها:}

أشارت نتائج السؤال الأول، إلى الأثر الكبير التعلُّم المصغر، عبر أدوات الجيل الثاني للويب (Web2.0)، في

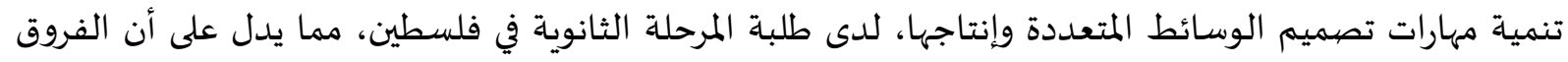

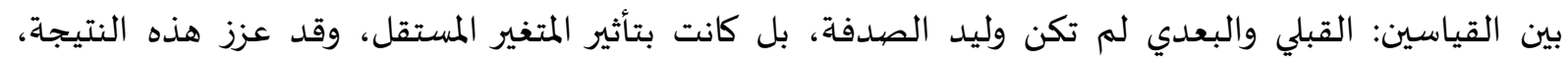

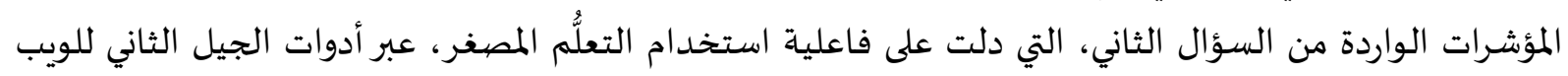

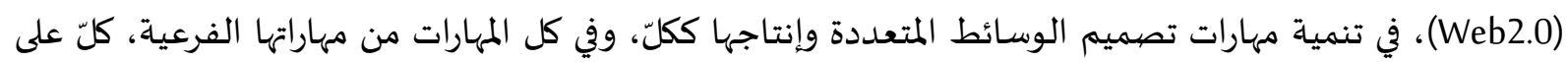

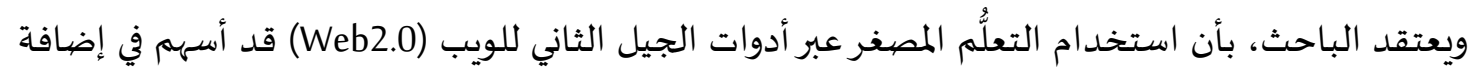

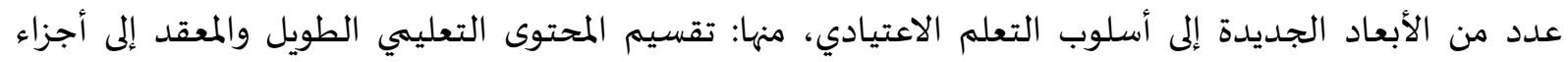

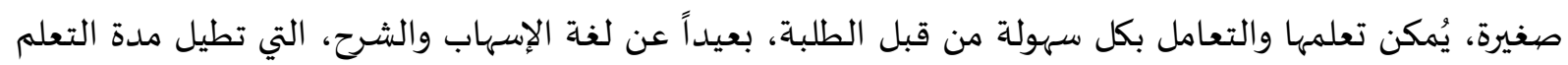

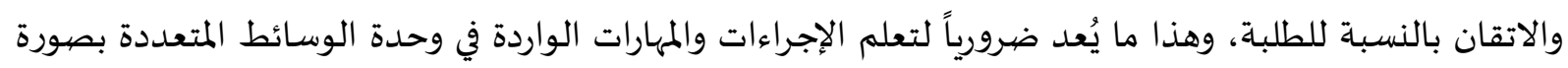

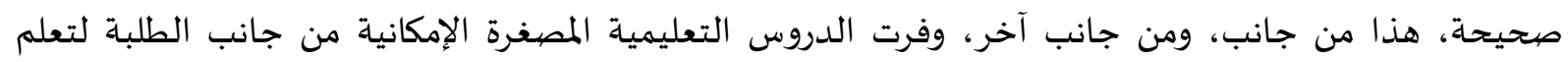

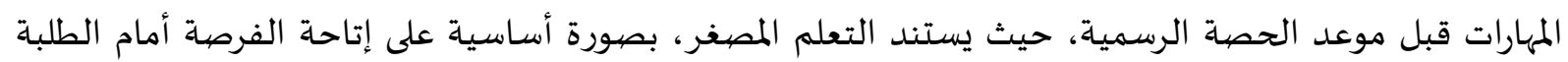

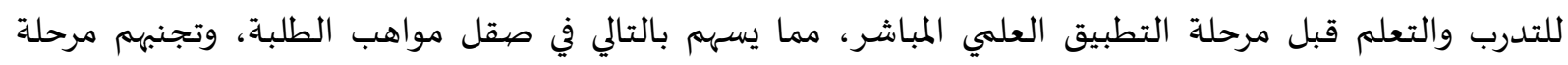
التوتروالقلق خلال أوقات الحصص المدرسية، مع إمكانية تعلم تلك المهارات بالوقت والمدة التي يحتاجونها، مما يعزز

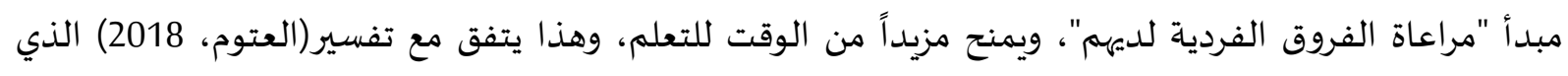

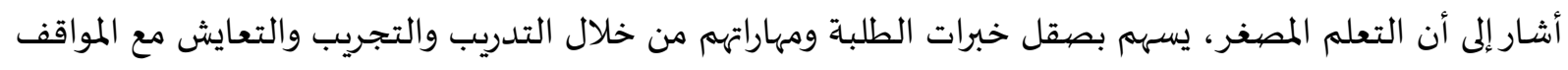

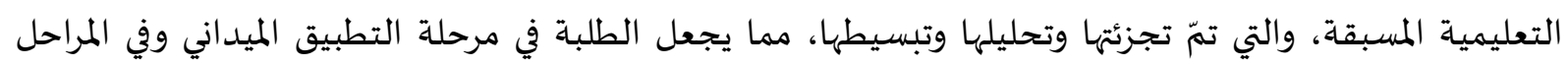

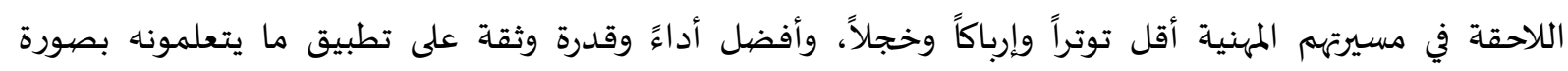

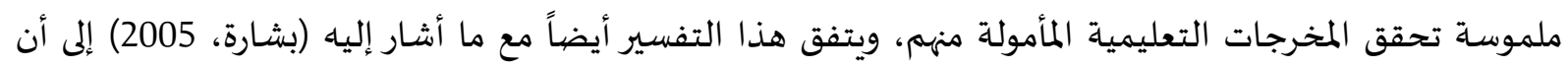

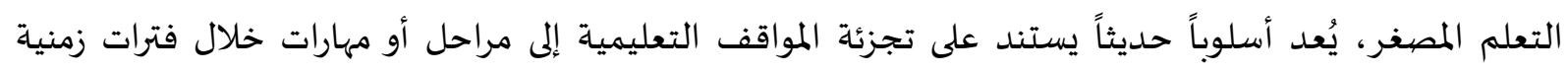

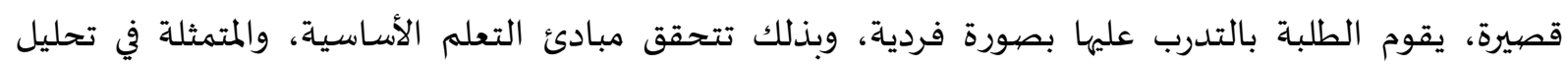

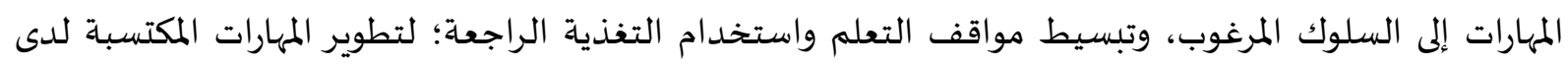

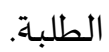

وعلاوة على ذلك، أسهم التعلم المصغر في جعل الطلبة مسؤولين عن تعلمهه، حيث يقومون بالتعلم

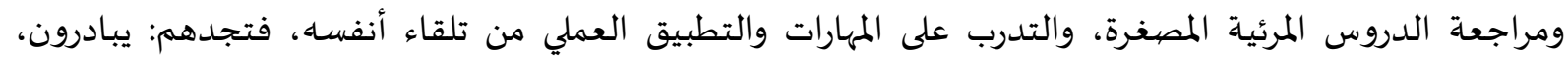

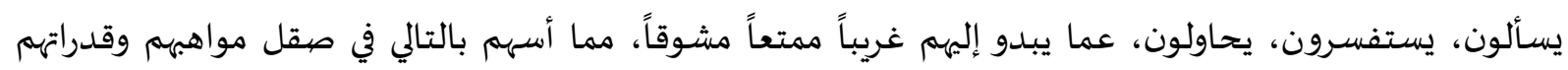
على التعله والتدريب والتطبيق.

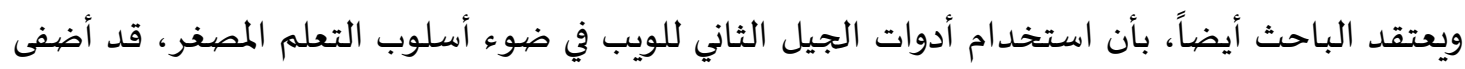

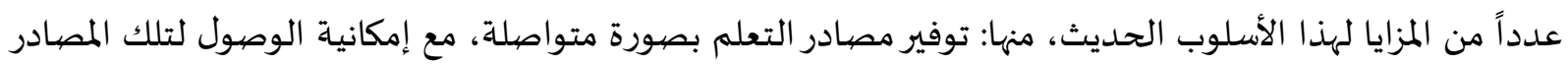

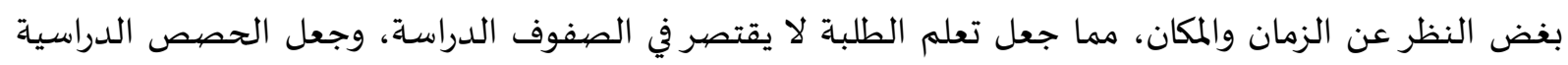

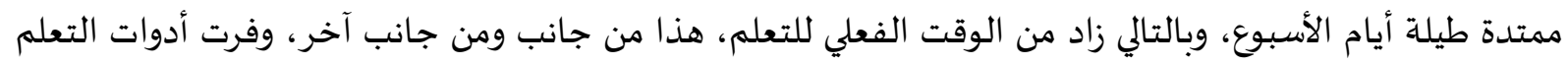

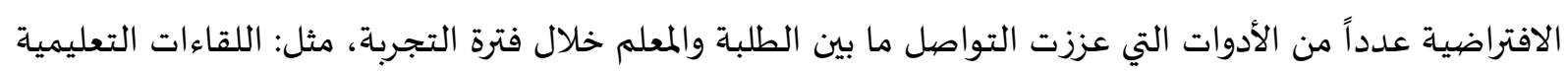

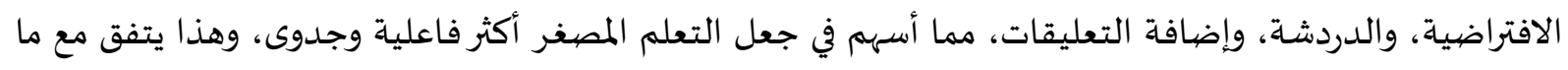

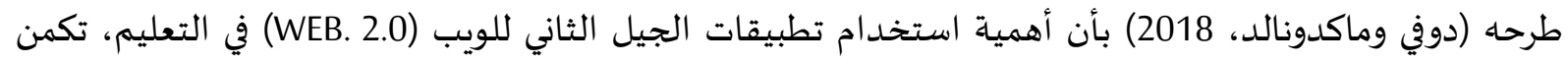


في تسهيلها عملية التواصل بين مختلف أطراف العملية التعليمياة، من خلال عدد من الأدوات الرقمية، التي يمكنها

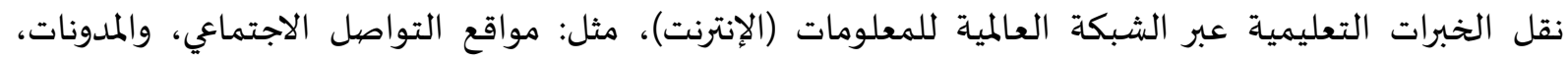

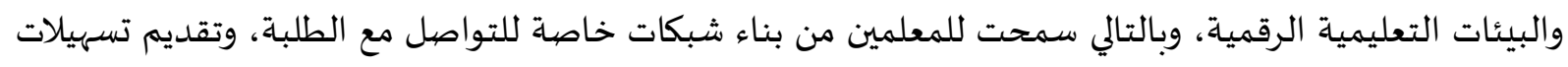

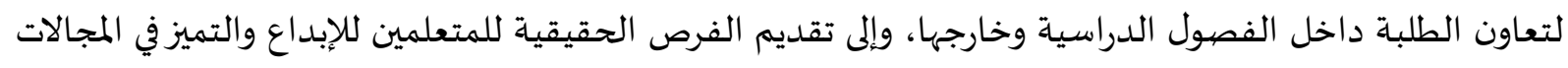

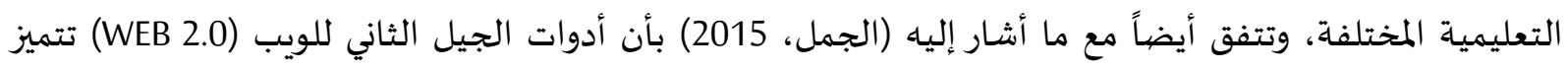

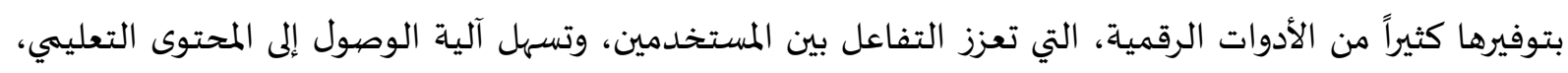

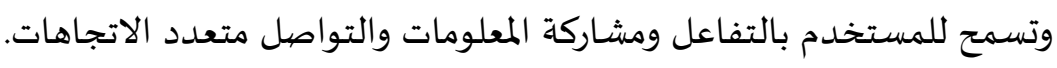
وبصورة عامة، تتفق نتائج هذا البحث مع كثير من الدراسات التي أشارت لفاعلية التعلم المصفر وأدوات

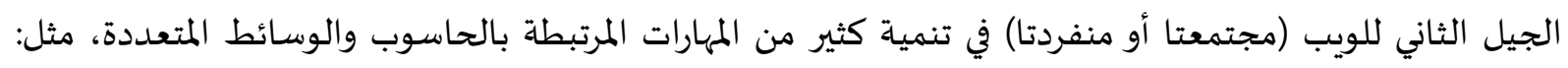

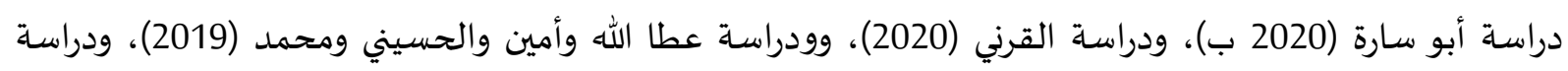

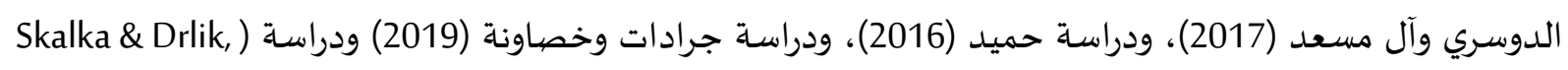

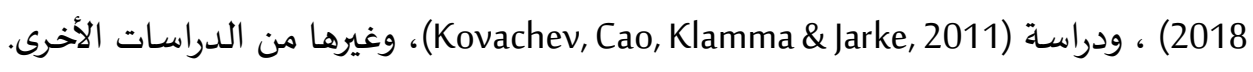

\section{التوصيات والمقترحات.}

في ضوء ما آلت إليه نتائج هذا البحث، يوصي الباحث ويقترح ما يأتي:

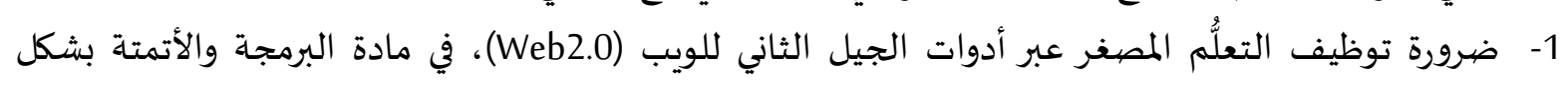

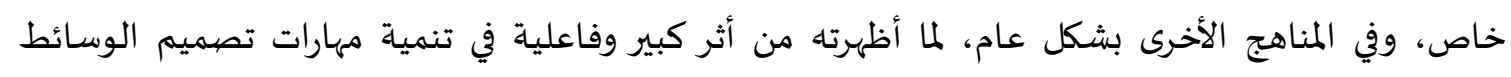
المتعددة وإنتاجها، لدى طلبة المرحلة الثانوية في فلسطين.

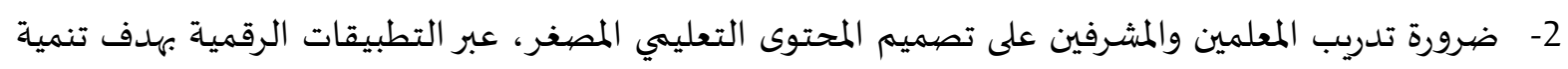
المهارات المختلفة لدى الطلبة في فلسطين.

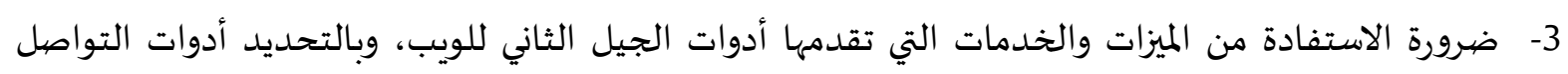

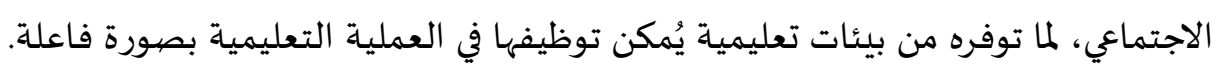

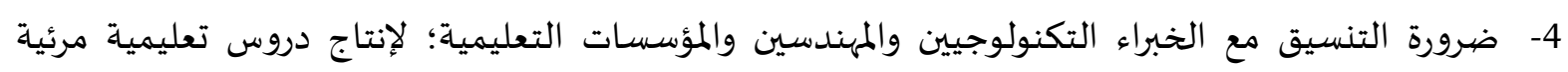
مصغرة تمكن الطلاب من مواصلة التعلم أثناء تواجدهم في المنازل.

$$
\text { 5- كما يقترح الباحث إجراء البحوث الآتية: }
$$

1. فاعلية أنشطة تعليمية قائمة على التعلم المصغر، في تنمية المهارات العملية لدوى لاتية طلبة المرحلة الأسـاسية في

فلسطين. 2. فاعلية برنامج تعليمي قائم على أدوات الجيل الثاني للويب، في تنمية مهارات حل المشكلات البرمجية، لدى طلبة المرحلة الثانوية في فلسطين. 3. فاعلية استخدام التعلم المصغر، عبر أدوات الجيل الثالث للويب في تنمية مهارات البرمجة كائنية التوجه لدى طلبة كلية تكنولوجيا المعلومات في فلسطين. 
- أبو سارة، عبد الرحمن محمد (2020 أ). تعليم البرمجة عبر بيئات الحوسبة السحابية: منحى جديد لتطوير

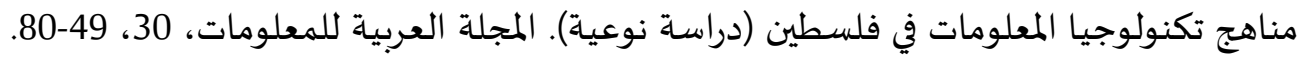
أبو سارة، عبد الرحمن محمد. (2020 ب). فاعلية استخدام استراتيجية التعلم المعكوس في تنمية مهارات تحليل الخوارزميات البرمجية وتصميمها لدى طلاب الصف الحادي عشر في فلسطين. مجلة العلوم التربوية والنفسية، .37-21، (39)4 أبو سارة، عبد الرحمن محمد. (2021). تصميم أنشطة تعليمية قائمة على البرمجة لتنمية المعرفة الإجرائية

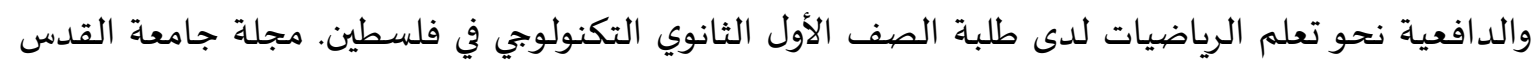

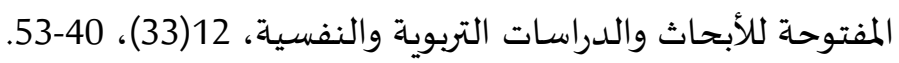

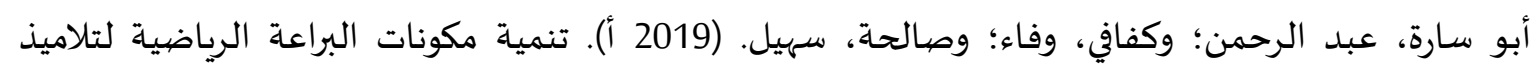

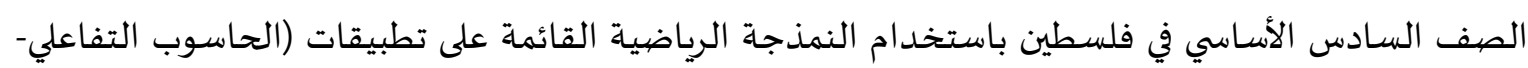

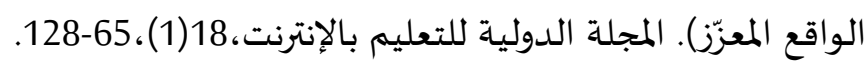
أبو سارة، عبد الرحمن؛ وكفافي، وفاء؛ وصالحة، سهيل. (2019 ب). فاعلية برنامج قائم على النمذجة الرياضية الرئية

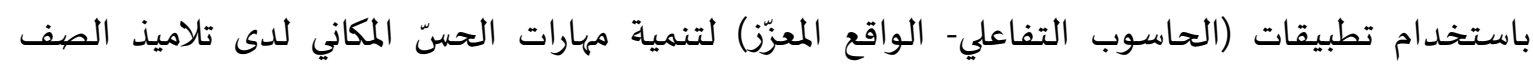
السادس الأساسي بمادة الرياضيات في فلسطين. المجلة الدولية للتعليم بالإنترنت،18(2)،1و-54.

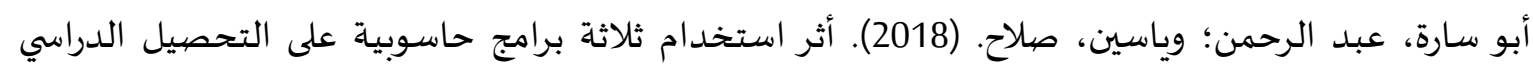

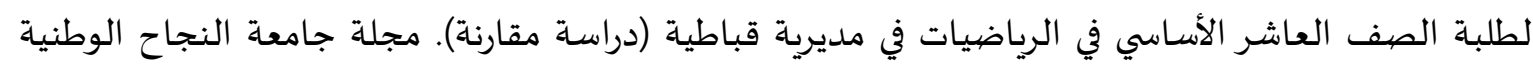

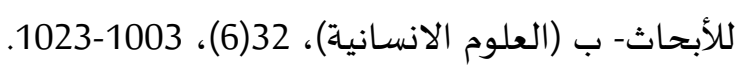

بشارة، عمر بشارة (2005). أثر التدريس المصغر باستخدام الفيديو في تنمية مهارات تدريس اللغة الإنجليزية. أطروحة دكتور اه غير منشورة، جامعة الخرطوم، السودان.

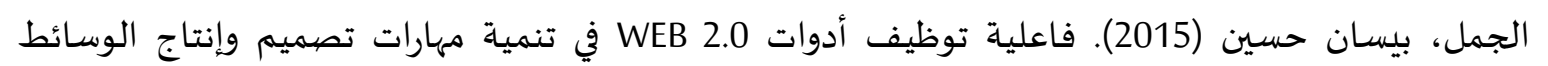
المتعددة في التكنولوجيا لدى طلبة الصف الثامن الأساسي بغزة. رسالة ماجستير غير منشورة، الجامعة الإسلامية، فلسطين.

دوفي، جودي وماكدونالد، جين (2018). التعليم والتعلم باستخدام التكنولوجيا. (ترجمة يوسف محممود عاروري). الطبعة الأولى، عمان، الأردن: دار الفكر (تاريخ النشر الأصلي 2018). 2018).

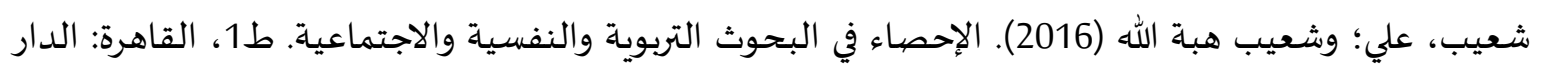
المصرية اللبنانية.

صالحة، سهيل حسين؛ وأبو سارة، عبد الرحمن محمد (2019). فاعلية استخدام منحى العلوم والتكنولوجيا

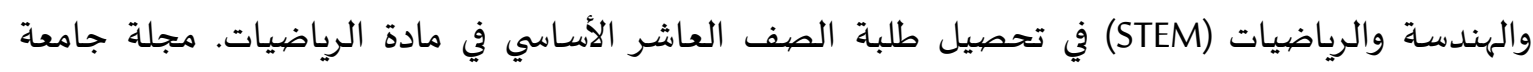

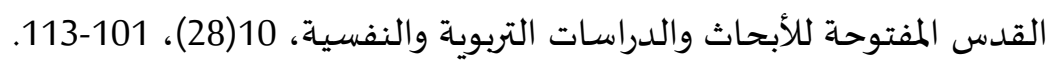

- العتوم، منذر سامح (2018). أثر استخدام التدريس المصغر في إكساب مهارات التدريس لطلبة التربية الفنية

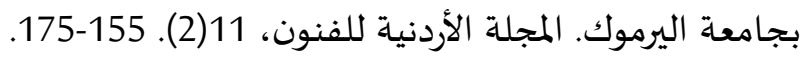


- العشي، دينا إسماعيل (2013). فاعلية برنامج بالوسائط المتعددة لتنمية المبادئ العلمية ومهارات التفكير البصري لدى طلاب الصف السادس الأساسي في مادة العلوم بغزة. ماجستير (غير منشورة)، الجامعة الإسلامية،

فلسطين.

عطا الله، أحمد؛ أمين، زينب؛ الحسيني، إيناس؛ ومحمد، رمضان (2019). فاعلية بيئة تعلم مصغر قائمة على

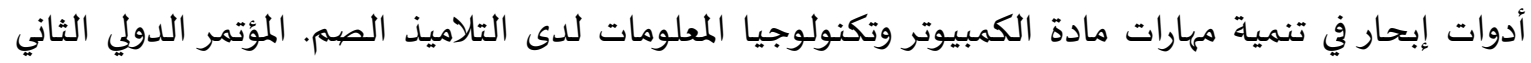

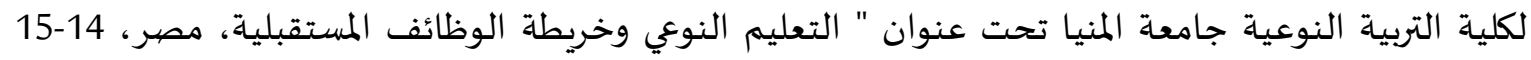
إبريل، 2019.

عودة، محمد خليل (2016). أثر التدريس باستخدام الوسائط المتعددة على التحصيل الدراسي في مجال الإعلام التلفزيوني لدى طلبة كلية الإعلام في جامعة النجاح الوطنية. رسالة ماجستير (غير منشورة)، جامع النجاح النداح الوطنية، فلسطين. فارس، نجلاء محمد؛ وإسماعيل، عبد الرؤوف محمد (2017). التعليم الإلكتروني مستحدثات في النظرية

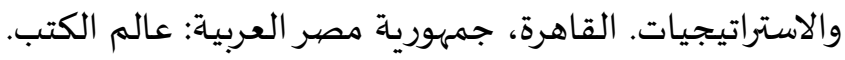

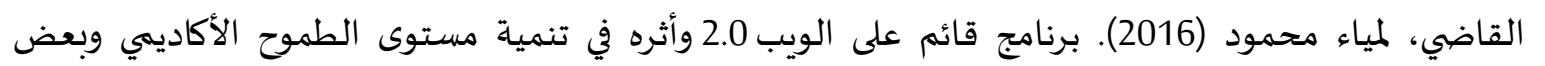
المهارات الحياتية لدى طالبات كلية الاقتصاد المنزلي. مجلة كلية التربية - جامعة الأزهر، القرني، علي بن سويعد (2020). أثر استخدام التعليم المصغر Microlearning على تنمية مهارات البرمجة المهارية

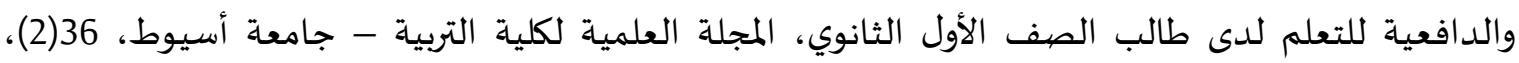
$.492-464$ محممد، أحمد محمد (2017). المهارات اللازمة لإنتاج الدروس الإلكترونية التفاعلية متعددة الوسائط لدى طلاب تكنولوجيا التعليم، مجلة كلية التربية- جامعة الأزهر، 2017). المشهراوي، حسن سلمان (2017). فاعلية برنامج قائم على الوسائط المتعددة في تنمية مهارات الاستماع لدى لدياء طلاب الصف السادس الأساسي، رسال ماجستير (غير منشورة)، الجامعة الإسلامياة، فلسطين.

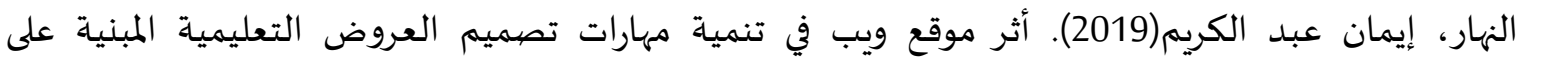
الإنفوجرافيك لدى طلبة تخصص تكنولوجيا التعليم في الجامعات الأردنية. رسالة ماجستير (غير منشورة)، جامعة الشرق الأوسط، عمان، الأردن. وزارة التربية والتعليم الفلسطينية (2021). طبيعة أسئلة امتحان شهادة الدراسة الثانوية العامة لعانة لعام 2021م. رام الله، فلسطين.

\section{ثانياً- المراجع بالإنجليزية:}

- Abu Sarah, A. M. (2021). Designing Programmed-Based Educational Activities to Develop Procedural Knowledge and Motivation Towards Learning Mathematics Among Eleventh Grade TechnologyStream Students in Palestine. Journal of Al-Quds Open University for Educational \& Psychological Research \& Studies, 12(33), 40-53.

- Abu Sarah, A. M. S. A. (2020 A). Education of Programming Through Cloud Computing Environments: A New Trend to Develop Information Technology Curricula in Palestine (Qualitative Research). Arab Journal of Information, 30, 49-80. 
- Abu Sarah, A. M. S. A. (2020 B). Effectiveness of Using Flipped Learning Strategy in Developing Skills of Programmatic Algorithms Analysis and Design for Eleventh Grade Students in Palestine: فاعلية استخدام استراتيجية التعلُم المعكوس في تنمية مهارات تحليل الخوارزميات البرمجية وتصهيمها لدى طلاب

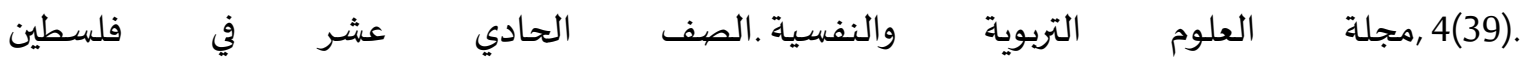
https://doi.org/10.26389/AJSRP.B140520

- Abu Sarah, A., \& Yaseen, S. (2018). The Impact of Using Three Computer Programs on the Academic Achievement of Tenth Grade Students in Math in Qabatia Directorate (Comparative Study). An-Najah University Journal for Research-B (Humanities), 32(6), 1004-1032.

- Abu Sarah, Abdelrahman, Kafafy, Wafaa \& Salha, Soheil. (2019 B). Efficacy of A Mathematical modeling-based Program Involves Applications of (Interactive Computer - Augmented Reality) And Its Role In Developing Spatial Sense Among Sixth Grade Mathematics Students In Palestine. International Journal of Internet Education, 18(2), 1-54. http://doi.org/10.21608/JAEE.2019.98859.

- Abu Sarah, Abdelrahman., Kafafy, Wafaa \& Salha, Soheil (2019 A). Developing Mathematical Proficiency Strands Among Sixth grade students in Palestine Using Mathematical Modeling based on applications (Interactive Computer - Augmented Reality). International Journal of Internet Education, 18(1), 65-128. http://doi.org/10.21608/JAEE.2019.68794

- Kamilali, D., \& Sofianopoulou, C. (2015). Micro learning as Innovative Pedagogy for Mobile Learning in MOOCs. International Association for Development of the Information Society.

- Khan, F. M. A., \& Masood, M. (2015). The effectiveness of an interactive multimedia courseware with cooperative mastery approach in enhancing higher order thinking skills in learning cellular respiration. Procedia-Social and Behavioral Sciences, 176, 977-984.

- Kovachev, D., Cao, Y., Klamma, R., \& Jarke, M. (2011). Learn-as-you-go: new ways of cloud-based micro-learning for the mobile web. In International conference on web-based learning (pp. 51-61). Springer, Berlin, Heidelberg.

- Lee, Y. H., Hsiao, C., \& Ho, C. H. (2014). The effects of various multimedia instructional materials on students' learning responses and outcomes: A comparative experimental study. Computers in Human Behavior, 40, 119-132.

- Leong, K. E., \& Alexander, N. (2014). College students attitude and mathematics achievement using web based homework. Eurasia Journal of Mathematics, Science and Technology Education, 10(6), 609-615.

- Mohammed, G. S., Wakil, K., \& Nawroly, S. S. (2018). The effectiveness of micro learning to improve students' learning ability. International Journal of Educational Research Review, 3(3), 32-38.

- Salha, S. H., \& Abu Sara, A. A. M. (2019). The effectiveness of using science, technology, engineering, and mathematics (STEM) approach on the achievement of students of the tenth grade in 
mathematics. Journal of Al-Quds Open University for Educational \& Psychological Research \& Studies, 10(28), 8.

- Skalka, J., \& Drlík, M. (2018). Educational model for improving programming skills based on conceptual microlearning framework. In International Conference on Interactive Collaborative Learning (pp. 923-934). Springer, Cham.

- So, H. J., Lee, H., \& Roh, S. Z. (2020). Examining the Design of Microlearning for Korean Adult Learners. 